OPEN ACCESS

Edited by:

Julie Ho,

University of Manitoba, Canada

Reviewed by:

Myra Coppage,

University of Rochester, United States

Rhonda Holdsworth,

Australian Red Cross Blood Service,

Australia

*Correspondence:

Sebastiaan Heidt

s.heidt@/umc.n

tORCID:

Suzanne Bezstarosti

orcid.org/0000-0002-0315-115X

Cynthia S. M. Kramer

orcid.org/0000-0003-1350-2336

Dave L. Roelen

orcid.org/0000-0002-1846-1193

Frans H. J. Claas

orcid.org/0000-0003-4157-6201

Sebastiaan Heidt

orcid.org/0000-0002-6700-188X

${ }^{\ddagger}$ These authors have contributed equally to this work and share

first authorship

This article was submitted to Alloimmunity and Transplantation,

a section of the journal

Frontiers in Immunology

Specialty section:

Received: 20 August 2021

Accepted: 06 December 2021

Published: 07 January 2022

Citation:

Bezstarosti S, Kramer CSM, Franke-van Dijk MEI, Vergunst M, Bakker KH, Uyar-Mercankaya M, Buchli R, Roelen DL, de Fijter JW,

Claas FHJ and Heidt S (2022)

HLA-DQ-Specific Recombinant

Human Monoclonal Antibodies

Allow for In-Depth Analysis

of HLA-DQ Epitopes.

Front. Immunol. 12:761893.

doi: 10.3389/fimmu.2021.761893

\section{HLA-DQ-Specific Recombinant} Human Monoclonal Antibodies Allow for In-Depth Analysis of HLA-DQ Epitopes

\author{
Suzanne Bezstarosti ${ }^{1,2 t \neq}$, Cynthia S. M. Kramer ${ }^{1+\neq}$, Marry E. I. Franke-van Dijk ${ }^{1}$, \\ Manon Vergunst ${ }^{1}$, Kim H. Bakker ${ }^{1}$, Merve Uyar-Mercankaya ${ }^{1}$, Rico Buchli ${ }^{3}$, \\ Dave L. Roelen ${ }^{1 \dagger}$, Johan W. de Fijter ${ }^{2}$, Frans H. J. Claas ${ }^{1,4 t}$ and Sebastiaan Heidt ${ }^{1,4 \times t}$ \\ ${ }^{1}$ Department of Immunology, Leiden University Medical Center, Leiden, Netherlands, ${ }^{2}$ Department of Internal Medicine \\ (Nephrology), Leiden University Medical Center, Leiden, Netherlands, ${ }^{3}$ Pure Protein LLC, Oklahoma City, OK, United States, \\ ${ }^{4}$ Eurotransplant Reference Laboratory, Leiden, Netherlands
}

HLA-DQ donor-specific antibodies (DSA) are the most prevalent type of DSA after renal transplantation and have been associated with eplet mismatches between donor and recipient $H\llcorner A$. Eplets are theoretically defined configurations of surface exposed amino acids on HLA molecules that require verification to confirm that they can be recognized by alloantibodies and are therefore clinically relevant. In this study, we isolated HLA-DQ specific memory $B$ cells from immunized individuals by using biotinylated $H\llcorner A-D Q$ monomers to generate 15 recombinant human HLA-DQ specific monoclonal antibodies $(\mathrm{mAb})$ with six distinct specificities. Single antigen bead reactivity patterns were analyzed with HLA-EMMA to identify amino acids that were uniquely shared by the reactive HLA alleles to define functional epitopes which were mapped to known eplets. The HLADQB1*03:01-specific mAb LB_DQB0301_A and the HLA-DQB1*03-specific mAb LB_DQB0303_C supported the antibody-verification of eplets 45EV and 55PP respectively, while mAbs LB_DQB0402_A and LB_DQB0602_B verified eplet 55R on HLA-DQB $1{ }^{*} 04 / 05 / 06$. For three mAbs, multiple uniquely shared amino acid configurations were identified, warranting further studies to define the inducing functional epitope and corresponding eplet. Our unique set of HLA-DQ specific mAbs will be further expanded and will facilitate the in-depth analysis of HLA-DQ epitopes, which is relevant for further studies of HLA-DQ alloantibody pathogenicity in transplantation.

Keywords: monoclonal antibody, human leukocyte antigen (HLA), epitope, eplet, transplantation, amino acid, antibody verification, reactivity pattern

\section{INTRODUCTION}

Chronic rejection remains a leading cause of graft loss in long-term renal transplant recipients and is associated with development of de novo donor-specific antibodies (dnDSA) (1-3). In order to minimize the chance of developing dnDSA, kidney allocation systems aim to match for human leukocyte antigen (HLA). Most HLA matching algorithms are restricted to HLA-A, -B and -DR on 
the serological antigen level, whereas dnDSA directed against HLA-DQ are the most prevalent after transplantation and have been associated with rejection, transplant glomerulopathy and allograft loss (4-9).

The induction of dnDSA is caused by mismatched amino acids (AA) on polymorphic sites of the donor HLA molecules. Configurations of surface exposed polymorphic AAs within a 3.0-3.5 Ångstrom ( $\AA$ ) radius have been defined as HLA eplets $(10,11)$. Multiple studies have demonstrated an association between eplet mismatches and formation of dnDSA (12-17). However, not all theoretically defined eplets are immunogenic and thus verification of actual interactions with antibodies is needed to determine the clinically relevant eplets (18-20). For HLA class I, a large number of eplets has been verified by several different methods (21-27). So far, only a limited number of HLADQ eplets have been antibody-verified, mainly due to the lack of proper reagents. Nevertheless, the few currently verified HLA-DQ eplets have been shown to be independently associated with an increased rate of dnDSA occurrence, graft rejection and graft failure $(17,28)$. However, a residual effect of non-antibody-verified HLA-DQ mismatches on graft loss has also been demonstrated (28), indicating that there are still immunogenic HLA-DQ eplets that have not yet been antibody-verified. Accordingly, identification of clinically relevant HLA-DQ eplets would be instrumental for a better assessment of immunological risk in transplant patients and facilitate personalized medicine such as personalized immunosuppressive drug dosing $(16,29,30)$.

Several approaches of antibody verification have been implemented through the years, ranging from serum analysis of uni- and multiparous women, absorption-elution studies, as well as analysis of reactivity patterns of murine and human monoclonal antibodies (mAbs) (20-27, 31-34). Amongst these, we consider human HLA-specific mAbs the most conclusive tool for antibody-verification of theoretically defined eplets $(23,24$, 31). Our group recently demonstrated a new method for the generation of HLA-DR specific recombinant human mAbs through isolation of HLA-DR specific memory B cells from peripheral blood utilizing HLA-DR tetramers. Thorough analysis of these mAbs resulted in antibody verification and redefinition of various HLA-DR eplets (35). In this study, we expanded our established techniques to generate novel recombinant human HLA-DQ mAbs by using biotinylated soluble HLA-DQ monomers. Overall, 15 recombinant human HLA-DQ mAbs were produced showing six distinct reactivity patterns in luminex single antigen bead (SAB) analysis. Further analysis of AA sequences of the reactive and non-reactive alleles identified uniquely shared AAs which were mapped to previously defined eplets. To determine the functional epitopes of the mAbs, uniquely shared AAs were identified through analysis of $\mathrm{AA}$ sequences of the reactive and non-reactive alleles, which were mapped to previously defined eplets.

\footnotetext{
Abbreviations: $\AA$, angstrom; AA, amino acid; BCM, background corrected mean fluorescence intensity; CDC, complement-dependent cytotoxicity; DSA, donorspecific antibodies; EBV-LCL, Epstein-Barr virus-transformed lymphoblastoid cell line; FACS-XM, flow cytometric cross match; mAb, monoclonal antibody; MFI, mean fluorescence intensity; $\mathrm{SAB}$, single antigen beads.
}

\section{MATERIALS AND METHODS}

\section{Subjects}

Peripheral blood and serum samples from healthy women $(\mathrm{N}=5)$ who developed HLA-DQ antibodies upon pregnancy, were collected with informed consent under guidelines issued by the medical ethics committee of Leiden University Medical Center (Leiden, the Netherlands). Peripheral blood mononuclear cells (PBMC) were isolated by Ficoll-Paque (Pharmacy Leiden University Medical Centre, Leiden, the Netherlands) density gradient centrifugation and kept frozen in liquid nitrogen until further use.

\section{HLA Typing}

Both antibody-producers and HLA immunizers were typed by next-generation sequencing on an Illuminia platform (Illumina, San Diego, CA, USA) using NGSgo kits (GenDx, Utrecht, the Netherlands) as previously described (35). IPD-IMGT/HLA database version 3.35.0 and 3.39.0 were used for analysis.

\section{Isolation and Expansion of HLA-DQ- Specific Memory B Cells}

HLA-DQ-specific memory B cells were isolated and expanded as previously described by Kramer et al. (35) with a few adaptations. From thawed PBMC, B cells were enriched (purity of $>95 \%$ ) by negative selection using EasySep Human B cell enrichment kits (Stem Cell Technologies, Grenoble, France). The enriched B cells were first incubated with $1 \mu \mathrm{g}$ of biotinylated soluble HLA-DQ monomers per $2 \times 10^{6}$ cells (Pure Protein LLC, Oklahoma City, OK, USA) for $30 \mathrm{~min}$ at $4^{\circ} \mathrm{C}$. Cells were washed with phosphatebuffered saline (PBS) containing $0.1 \%$ bovine serum albumin (Sigma-Aldrich, Zwijndrecht, the Netherlands), and stained with streptavidin-PE, streptavidin-APC, mouse anti-human CD3 (Pacific blue, SP34-2), IgD (PE-Cy7, IA6-2) (all from BD Biosciences, Breda, the Netherlands), and CD27 (FITC, CLB27/1, ThermoFisher Scientific, Waltham, MA, USA) for $30 \mathrm{~min}$ at $4^{\circ} \mathrm{C}$ in the dark. After washing, $\mathrm{CD}^{-} \mathrm{CD} 27^{+} \mathrm{IgD}^{-} \mathrm{APC}^{+} \mathrm{PE}^{+}$ cells were sorted by FACSAria III sorter (BD Biosciences) at 1 cell per well in 96-well flat-bottom plates (Costar, Corning, NY, USA) containing $0.1 \times 10^{6}$ irradiated CD40L-expressing EL4-B5 cells (36). The memory B cell clones were expanded for 13 days with Iscove's modified Dulbecco's medium (IMDM; Gibco Invitrogen, Paisley, UK) supplemented with $10 \%$ fetal bovine serum (FBS; Sigma-Aldrich), $2 \mathrm{mM}$ L-glutamine (Gibco), $50 \mu \mathrm{M}$ 2-mercaptoethanol (Sigma-Aldrich), and $100 \mathrm{U} / \mathrm{ml}$ penicillin with $100 \mu \mathrm{g} / \mathrm{ml}$ streptomycin (Gibco), $0.5 \mu \mathrm{g} / \mathrm{ml}$ R848 (toll-like receptor $7 / 8$ agonist, resiquimod), $20 \mu \mathrm{g} / \mathrm{ml}$ insulin-transferrinsodium selenite (both from Sigma-Aldrich), $50 \mathrm{ng} / \mathrm{ml} \mathrm{IL-21}$ (Gibco), $1 \mathrm{ng} / \mathrm{ml} \mathrm{IL}-1 \beta$, and $0.3 \mathrm{ng} / \mathrm{ml} \mathrm{TNF} \alpha$ (both from Miltenyi, Leiden, the Netherlands) (37).

\section{HLA-Specific Antibody Detection}

The supernatant of the memory B cell clones or recombinant human HLA-specific mAbs were screened for the presence of IgG by enzyme-linked immunosorbent assay, as previously described (38). Subsequently, the IgG-positive supernatants were tested with Lifecodes Lifescreen Deluxe screening kit 
(Immucor Transplant Diagnostics, Stamford, CT, USA) to detect HLA antibodies. The specificities of HLA antibodies were determined by Lifecodes HLA class II SAB assays (Immucor). Serum samples were treated with ethylenediaminetetraacetic acid (6\% EDTA) prior to testing. Supplementary Table 1 lists the alleles present in the SAB panel that was used. HLA antibody data was analyzed with Match It! Antibody software version 1.3.0 (Immucor), with positive HLA alleles assigned according to the software.

\section{Production of Recombinant Human Monoclonal HLA Antibodies}

RNA from HLA-antibody positive memory B cell clones was isolated using TRIzol (ThermoFisher Scientific). Subsequently, human mAbs were generated using recombinant technology as previously described (39). Briefly, genes encoding the variable heavy and light chains were obtained by SMART cDNA synthesis and 5'-RACE polymerase chain reaction, which were then cloned into pcDNA3.3 expression containing the corresponding human constant domain IgG1, kappa or lambda. Next, plasmids of the heavy and light chain were generated and used for transient co-transfection of ExpI293F cells (ThermoFisher Scientific) with SV40-LT plasmid (40), ExpiFectamine, Opti-Mem, Expi293 expression medium (all ThermoFisher Scientific) to produce recombinant human mAbs. Sanger sequencing (Macrogen, Amsterdam, the Netherlands) of heavy and light chain plasmids was performed to obtain nucleotide sequence data of the variable domain. Sequence data was analyzed with IgBLAST (41) to define V(D)J gene usage.

\section{Reactivity Analysis of Recombinant Human HLA-DQ mAbs}

HLA-EMMA version 1.05 was used to determine the solvent accessible AA mismatches between the HLA-DQ alleles of the antibody producer and the mismatched HLA-DQ allele(s) of the immunizer, or the HLA-DQ monomer that was used for memory B cell sorting (42). Next, it was determined whether these solvent accessible AA mismatches were uniquely shared by the reactive HLA alleles and absent on the non-reactive HLA alleles. In order to visualize AA positions and to establish whether AAs were within a $3.5 \AA$ or $15 \AA$ radius to form a functional or structural epitope respectively, the following HLADQ crystal structures were visualized in Swissviewer (43): Protein Data Bank (PBD) 1S9V, 4Z7U and 1UVQ (downloaded from https://www.rcsb.org/on February 24, 2021). Antibody reactivity patterns of the mAbs were analyzed with HLAMatchmaker (DRDQDP Antibody Analysis Program v3.1; http://www.epitopes.net/) to identify eplets present on the reactive HLA alleles. Polymorphic residue definition and antibody-verification status of eplets were extracted from the HLA Epitope Registry (http://www.EpRegistry.com.br accessed on May 6, 2021).

\section{Cells}

HLA-typed Epstein-Barr virus-transformed lymphoblastoid cell lines (EBV-LCLs) were cultured in IMDM supplemented with
10\% FBS, 2 mM L-glutamine, $50 \mu \mathrm{M}$ 2-mercaptoethanol, and $100 \mathrm{U} / \mathrm{ml}$ penicillin with $100 \mu \mathrm{g} / \mathrm{ml}$ streptomycin.

\section{Flow Cytometric Crossmatch Assay (FACS-XM)}

As previously described (35), EBV-LCLs were first incubated with $\mathrm{mAb}(20 \mu \mathrm{g} / \mathrm{ml})$ or PBS at room temperature (RT) for 30 min. After washing, the cells were stained with mouse antihuman CD3 (PE, SK7), CD19 (APC, HIB19, both from BD Bioscience), and rabbit anti-human IgG F(ab')2 (FITC, Dako, Leiden, the Netherlands) at $4^{\circ} \mathrm{C}$ in the dark for $30 \mathrm{~min}$. Next, the washed cells were fixed with $1 \%$ paraformaldehyde (Pharmacy LUMC) and acquired using Accuri C6 flow cytometry (BD Bioscience). Data were analyzed using FlowJo V10 software (Ashland, OR, USA).

\section{Complement-Dependent Cytotoxicity Assay}

Complement-dependent cytotoxicity (CDC) assays were performed as previously described (35). EBV-LCLs were incubated with various concentrations of mAbs (0.3125 - 0.625 - 1.25 - 2.5 - 5 - 10 - $20-40 \mu \mathrm{g} / \mathrm{ml}$ ) or PBS in Terasaki plates (Greiner, Frickenhausen, Germany) for $60 \mathrm{~min}$ at RT. Cells were then incubated for another $60 \mathrm{~min}$ at RT with $5 \mu \mathrm{l} \mathrm{rabbit}$ complement (Inno-train, Kronberg, Germany). Cytotoxicity of EBV-LCLs was visualized after $15 \mathrm{~min}$ in the dark at RT incubation with $5 \mu$ propidium iodide ink (Sigma-Aldrich), and analyzed with the Patimed (Leica Microsystems, Amsterdam, the Netherlands).

\section{RESULTS}

\section{Recombinant Human HLA-DQ-Specific mAbs Generated From HLA-Specific Memory B Cell Clones}

A total of 15 recombinant human HLA-DQ-specific mAbs (Table 1) were generated from unique HLA-DQ-specific memory B cell clones isolated from five individuals using six different HLA-DQ monomers (Table 2). HLA specificity in the serum of the immunized subjects and HLA specificity of the generated HLA-DQ-specific mAbs was confirmed by SAB analysis (Supplementary Figure 1), which demonstrated that all mAbs were directed against the beta chain of the HLA-DQ molecule and none were cross-reactive against HLA-DR or HLA-DP alleles. These findings were further supported by FACS-XM and CDC assays which confirmed binding to the natively expressed target-HLA molecule and their cytotoxic capacity (Supplementary Figures 2, 3). When multiple mAbs with identical reactivity patterns were generated from one individual, only one $\mathrm{mAb}$ will be discussed in detail.

Reactivity Analysis of mAb LB_DQB0201_A The mAb LB_DQB0201_A displayed a narrow reactivity pattern in the $\mathrm{SAB}$ assay, solely recognizing $\mathrm{DQB} 1^{\star} 02: 01$ and $\mathrm{DQB} 1^{\star} 02: 02$ (Figure 1A). We confirmed the binding of 
On reactive HLA-DQB1 Alleles

\begin{tabular}{|c|c|c|c|c|c|c|c|}
\hline Human mAb & $\begin{array}{l}\text { HLA-DQ Antibody } \\
\text { Producer }\end{array}$ & HLA Immunizer & $\begin{array}{c}\text { HLA } \\
\text { Monomer }\end{array}$ & Reactive HLA-DQB1 Alleles & $\begin{array}{l}\text { HLAMatchmaker } \\
\text { Version } 3.1 \text { eplet }\end{array}$ & $\begin{array}{l}\text { HLA Epitope Registry } \\
\text { Eplet }\end{array}$ & $\begin{array}{l}\text { Uniquely } \\
\text { Shared } \\
\text { Residues }\end{array}$ \\
\hline $\begin{array}{l}\text { LB_DQB0201_A } 1 \\
\text { LB_DQB0201_B } \\
\text { LB_DQB0201_C }\end{array}$ & $\begin{array}{l}\text { Individual \#1 } \\
\text { DQB1 }{ }^{*} 03: 01^{2}, \mathrm{DQB} 1^{*} 06: 02, \\
\mathrm{DQA} 1^{*} 01: 02, \mathrm{DQA} 1^{*} 05: 05\end{array}$ & & $\begin{array}{l}\mathrm{DQB} 1{ }^{*} 02: 01 / \\
\mathrm{DQA1}{ }^{*} 02: 01\end{array}$ & $\mathrm{DQB} 1^{*} 02: 01, \mathrm{DQB} 1^{*} 02: 02$ & 52LL (AbVer) & $\begin{array}{l}52 \mathrm{LL} \\
(52 \mathrm{~L} 55 \mathrm{~L} 28 \mathrm{~S} 30 \mathrm{~S} 37 \mathrm{I})\end{array}$ & $\begin{array}{l}46 \mathrm{E}, 52 \mathrm{~L}, 55 \mathrm{~L} \\
71 \mathrm{~K}, 74 \mathrm{~A}\end{array}$ \\
\hline $\begin{array}{l}\text { LB_DQB0301_A } \\
\text { LB_DQB0301_B } \\
\text { LB_DQB0301_C }\end{array}$ & $\begin{array}{l}\text { Individual \#2 } \\
\text { DQB1*03:02, DQB1*04:02, } \\
\text { DQA1*03:01, DQA } 1^{*} 03: 03\end{array}$ & $\begin{array}{l}\text { DQB1*03:01, DQB1*04:02, } \\
\text { DQA1*03:03, DQA1*05:05 }\end{array}$ & $\begin{array}{l}\text { DQB1 }{ }^{*} 03: 01 / \\
\text { DQA }{ }^{*} 02: 01\end{array}$ & $\mathrm{DQB1}{ }^{*} 03: 01$ & 45EV (AbVer) & $\begin{array}{l}\text { 45EV } \\
(45 \mathrm{E} 46 \mathrm{~V} 47 \mathrm{Y})\end{array}$ & $45 \mathrm{E}$ \\
\hline LB_DQB0303_A & $\begin{array}{l}\text { Individual \#3 } \\
\text { DQB1*06:02, DQB1*06:03, } \\
\text { DQA } 1^{*} 01: 02, \mathrm{DQA} 1^{*} 01: 03\end{array}$ & $\begin{array}{l}\mathrm{DQB} 1^{*} 03: 01^{3}, \mathrm{DQB} 1^{*} 06: 03 \\
\mathrm{DQA} 1^{*} 01: 03, \mathrm{DQA} 1^{*} 03: 03\end{array}$ & $\begin{array}{l}\text { DQB1*03:03/ } \\
\text { DQA } 1^{*} 02: 01\end{array}$ & $\begin{array}{l}\mathrm{DQB1}{ }^{\star} 02: 01, \mathrm{DQB} 1^{*} 02: 02, \mathrm{DQB} 1^{*} 03: 01 \\
\mathrm{DQB1}{ }^{*} 03: 02, \mathrm{DQB1} 1^{*} 03: 03, \mathrm{DQB} 1^{*} 04: 01 \\
\mathrm{DQB1} 1^{*} 04: 02\end{array}$ & $\begin{array}{l}\text { 84QL (AbVer) } \\
125 \mathrm{AQ} \text { (other) }\end{array}$ & $\begin{array}{l}\text { 84QL } \\
\text { (84Q 86E 87L 89T 90T 125A) }\end{array}$ & $\begin{array}{l}\text { 53L, 84Q, } \\
85 \mathrm{~L}, 86 \mathrm{E}, 87 \mathrm{~L}, \\
89 \mathrm{~T}, 90 \mathrm{~T}, 125 \mathrm{~A}, \\
220 \mathrm{H}, 221 \mathrm{H}\end{array}$ \\
\hline LB_DQB0303_B & $\begin{array}{l}\text { Individual \#3 } \\
\text { DQB1*06:02, DQB1*06:03, } \\
\text { DQA1*01:02, DQA1*01:03 }\end{array}$ & $\begin{array}{l}\mathrm{DQB} 1 * 03: 01^{3}, \mathrm{DQB} 1^{*} 06: 03 \\
\mathrm{DQA1} 1^{*} 01: 03, \mathrm{DQA} 1^{*} 03: 03\end{array}$ & $\begin{array}{l}\mathrm{DQB} 1{ }^{*} 03: 03 / \\
\mathrm{DQA} 1^{*} 02: 01\end{array}$ & $\begin{array}{l}\mathrm{DQB1}{ }^{*} 03: 01, \mathrm{DQB} 1^{*} 03: 02, \mathrm{DQB} 1{ }^{*} 03: 03 \\
\mathrm{DQB1} 1^{* 04}: 01, \mathrm{DQB1} 1^{*} 04: 02\end{array}$ & $\begin{array}{l}\text { 52PL (AbVer) } \\
182 \mathrm{~N} \text { (other) }\end{array}$ & $182 \mathrm{~N}$ & $\begin{array}{l}52 \mathrm{P}+53 \mathrm{~L}, 140 \mathrm{~T}, \\
182 \mathrm{~N}\end{array}$ \\
\hline $\begin{array}{l}\text { LB_DQB0303_C } \\
\text { LB_DQB0303_D }\end{array}$ & $\begin{array}{l}\text { Individual \#3 } \\
\text { DQB1*06:02, DQB1*06:03, } \\
\text { DQA1*01:02, DQA1*01:03 }\end{array}$ & $\begin{array}{l}\mathrm{DQB} 1^{*} 03: 01^{3}, \mathrm{DQB} 1^{*} 06: 03 \\
\mathrm{DQA} 1^{*} 01: 03, \mathrm{DQA} 1^{*} 03: 03\end{array}$ & $\begin{array}{l}\text { DQB } 1^{*} 03: 03 / \\
\text { DQA } 1^{*} 02: 01\end{array}$ & DQB1*03:01, DQB1*03:02, DQB1*03:03 & 55PP (AbVer) & 55PP (55P 56P) & $55 \mathrm{P}$ \\
\hline $\begin{array}{l}\text { LB_DQB0402_A } \\
\text { LB_DQB0402_B } \\
\text { LB_DQB0402_C }\end{array}$ & 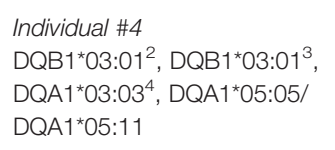 & $\begin{array}{l}\mathrm{DQB1} 1^{*} 03: 01^{2}, \mathrm{DQB} 1 * 06: 02 \\
\mathrm{DQA1} 1^{* 01}: 02, \mathrm{DQA} 1^{*} 05: 05\end{array}$ & $\begin{array}{l}\mathrm{DQB} 1{ }^{*} 04: 02 / \\
\mathrm{DQA} 1^{*} 02: 01\end{array}$ & $\begin{array}{l}\mathrm{DQB1} 1^{*} 04: 01, \mathrm{DQB} 1^{*} 04: 02, \mathrm{DQB} 1^{*} 05: 01 \\
\mathrm{DQB1}{ }^{*} 05: 02, \mathrm{DQB} 1^{*} 05: 03, \mathrm{DQB} 1^{*} 06: 01 \\
\mathrm{DQB1} 1^{*} 06: 02, \mathrm{DQB} 1^{*} 06: 03, \mathrm{DQB} 1^{*} 06: 04\end{array}$ & - & $55 R$ & $55 R$ \\
\hline LB_DQB0601_B & $\begin{array}{l}\text { Individual \#4 } \\
\text { DQB1*03:01², DQB1 }{ }^{*} 03: 01^{3} \\
\text { DQA } \\
\text { DQA } 03: 03^{*} 05: 11\end{array}$ & $\begin{array}{l}\text { DQB1*03:01 }{ }^{2}, \mathrm{DQB} 1^{*} 06: 02 \\
\mathrm{DQA1} 1^{*} 01: 02, \mathrm{DQA} 1^{*} 05: 05\end{array}$ & $\begin{array}{l}\text { DQB }{ }^{*} 06: 01 / \\
\text { DQA } 1^{*} 02: 01\end{array}$ & $\begin{array}{l}\text { DQB1*04:01, DQB1*04:02, DQB1*05:01, } \\
\text { DQB1*05:02, DQB1*05:03, DQB1*06:01, } \\
\text { DQB1*06:02, DQB1*06:03, DQB1*06:04 }\end{array}$ & - & $55 R$ & $55 R$ \\
\hline LB_DQB0602_B & $\begin{array}{l}\text { Individual \#5 } \\
\text { DQB1*02:01 } 1^{5}, \mathrm{DQB} 1^{*} 03: 01 \\
\text { DQA } 1^{*} 05: 01, \mathrm{DQA} 1^{*} 05: 05\end{array}$ & & $\begin{array}{l}\mathrm{DQB} 1{ }^{*} 06: 02 / \\
\mathrm{DQA} 1^{*} 01: 01\end{array}$ & 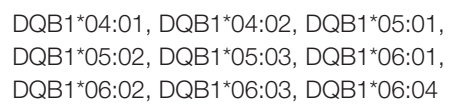 & - & $55 \mathrm{R}$ & $55 R$ \\
\hline
\end{tabular}

${ }^{1}$ Reactivity analyses of mAbs in bold are discussed.

${ }^{2}$ Typing is DQB1*03:01/03:297; these alleles do not have amino acid mismatches.

${ }^{3}$ Typing is DQB1*03:01/03:276N/03:292; DQB1*03:292 has 1 solvent-accessible amino acid mismatch on position 214.

${ }^{4}$ Typing is DQA1*03:03/03:11; these alleles have 1 not solvent-accessible amino acid mismatch on position 199.

${ }^{5}$ Typing is DQB1*02:01/02:109; these alleles have 1 solvent-accessible amino acid mismatch on position 204.

mAb, monoclonal antibody; AbVer, antibody-verified. 


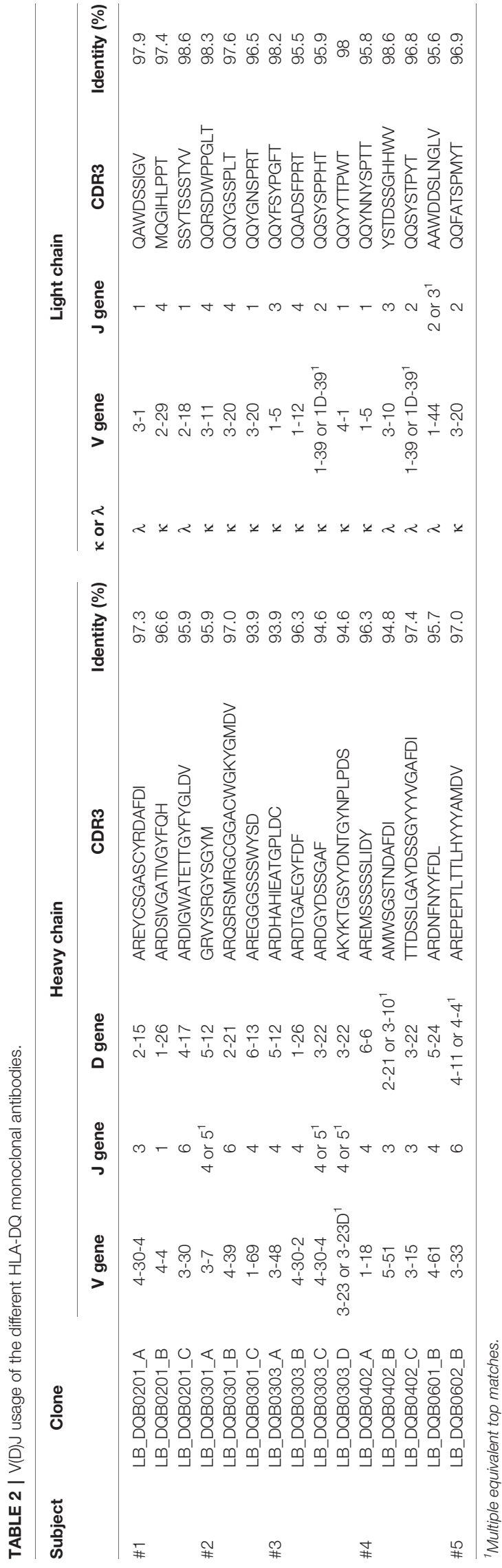

LB_DQB0201_A to its physiologically expressed HLA target in a FACS-XM and its cytotoxicity capacity in a CDC assay with EBV-LCLs expressing DQB1 ${ }^{\star} 02: 01$ (Figures 1B-D). Next, HLAEMMA was used to determine AA mismatches between $\mathrm{DQB1} 1^{*} 03: 01$ and $\mathrm{DQB1} 1^{*} 06: 02$ of the antibody-producer and DQB1 ${ }^{*} 02: 01$ of the HLA-DQ monomer used for cell sorting, as the immunizer's HLA type was unknown. Comparison of the AA sequences of $\mathrm{DQB1} 1^{\star} 02: 01$ and $\mathrm{DQB1} 1^{\star} 02: 02$ with the nonreactive $\mathrm{HLA}-\mathrm{DQB} 1$ alleles identified five of the $A \mathrm{~A}$ mismatches to be uniquely shared by the reactive HLA-DQB1 alleles in the SAB assay. These residues, glutamic acid (E) on position 46, leucine (L) on position 52 and position 55, lysine (K) on position 71 and alanine (A) on position 74 (Figure 1A) are all located on the top of the HLA-DQB1*02:01/DQA $1^{*} 05: 01$ molecule (Figure 1E). HLAMatchmaker analysis demonstrated that the reactive HLA-DQB1 alleles shared eplet 52LL (52L 55L $28 \mathrm{~S} 30 \mathrm{~S} 37 \mathrm{I})$, which comprises two of the five uniquely shared AAs that were identified with HLA-EMMA. Although uniquely shared by the reactive HLA-DQB1 alleles, we did not consider the other three residues (28S 30S 37I), because these positions have not been defined as solvent accessible by HLA-EMMA and thus cannot be accessed by the $B$ cell receptor to induce an antibody response. While HLAMatchmaker identified only eplet 52LL, we observed three possible functional epitopes for LB_DQB0201_A; 46E (Figure 1F), or 52L + 55L (Figure 1G), or $71 \mathrm{~K}+74 \mathrm{~A}$ (Figure $\mathbf{1 H}$ ). For each functional epitope, at least two or more of the other unique residues are located within a 15 $\AA$ radius. As the five uniquely shared residues are always present together on the HLA-DQB1 alleles represented in the currently available $\mathrm{SAB}$ assays, it is not possible to determine which of the functional epitopes induced the antibody response.

\section{Reactivity Analysis of mAb LB_DQB0301_A}

SAB analysis of mAb LB_DQB0301_A showed only reactivity against the immunizing allele $\mathrm{DQB} 1^{\star} 03: 01$, which was also confirmed with cellular assays (Figure 2A). Upon comparing the AA sequences of reactive and non-reactive HLA-DQB1 alleles in the SAB assay, $45 \mathrm{E}$ was identified to be unique for $\mathrm{DQB1}{ }^{*} 03: 01$. This residue is located on the top of the molecule (Figure 2B) and is the functional epitope of LB_DQB0301_A (Figure 2C). While the antibody-verified eplet 45EV (45E 46V $47 \mathrm{Y}$ ) was identified by HLAMatchmaker analysis as uniquely present on $\mathrm{DQB1}{ }^{\star} 03: 01$, residues $46 \mathrm{~V}$ and $47 \mathrm{Y}$ are self amino acids for the antibody-producer and are both present on nonreactive HLA-DQB1 alleles. Further, residue $47 \mathrm{Y}$ is defined as not solvent accessible by HLA-EMMA. Based on the SAB analysis of mAb LB_DQB0301_A however, it is not possible to determine whether residues $46 \mathrm{~V}$ and $47 \mathrm{Y}$ are crucial for antibody-induction or that $45 \mathrm{E}$ is sufficient and should be considered as the eplet. Since we cannot rule out that $46 \mathrm{~V}$ and $47 \mathrm{Y}$ are part of the functional epitope and the corresponding eplet, we conclude that mAb LB_DQB0301_A supports the antibody-verification of eplet 45EV.

Reactivity Analysis of mAb LB_DQB0303_A A more broadly reactive HLA-DQ-specific $m A b$ is LB_DQB0303_A, which binds to DQB1*02:01, DQB1 ${ }^{\star} 02: 02$, 
A

LB_DQB0201_A

\begin{tabular}{|c|c|c|c|c|c|c|c|c|}
\hline HLA Allele & $\mathrm{BCM}$ & FC-XM & CDC & 46 & 52 & 55 & 71 & 74 \\
\hline DQB1*02:01/DQA1*02:01 & 14128 & & & $E$ & $\mathrm{~L}$ & $\mathrm{~L}$ & $\mathrm{~K}$ & A \\
\hline DQB1*02:02/DQA1*05:01 & 13730 & & & $\mathrm{E}$ & L & L & $\mathrm{k}$ & A \\
\hline DQB1*02:02/DQA1*02:01 & 11471 & & & $\mathrm{E}$ & L & L & $\mathrm{K}$ & A \\
\hline DQB1*02:02/DQA1*03:02 & 11353 & & & $\mathrm{E}$ & L & L & $\mathrm{K}$ & A \\
\hline DQB1*02:01/DQA1*05:01 & 10348 & Positive & Positive & $\mathrm{E}$ & L & L & $\mathrm{k}$ & A \\
\hline DQB1*04:01/DQA1*02:01 & -94 & & & $v$ & $P$ & $\mathrm{R}$ & D & $\mathrm{s}$ \\
\hline DQB1*06:02/DQA1*01:02 & -118 & & & $\mathrm{v}$ & $\mathrm{P}$ & $\mathrm{R}$ & T & E \\
\hline DQB1*03:01/DQA1*06:01 & -126 & Negative & Negative & $\mathrm{v}$ & $P$ & $\mathrm{P}$ & T & $\mathrm{E}$ \\
\hline DQB1*03:01/DQA $1 * 05: 01$ & -136 & & & v & $\mathrm{P}$ & P & T & $\mathrm{E}$ \\
\hline DQB1*03:03/DQA1*03:02 & -177 & & & v & $P$ & $\mathrm{P}$ & T & $\mathrm{E}$ \\
\hline Other DQ beads & $\leq 0$ & & & $\mathrm{v}$ & $P$ & $P / R$ & $A / D / T$ & $E / S$ \\
\hline
\end{tabular}

B

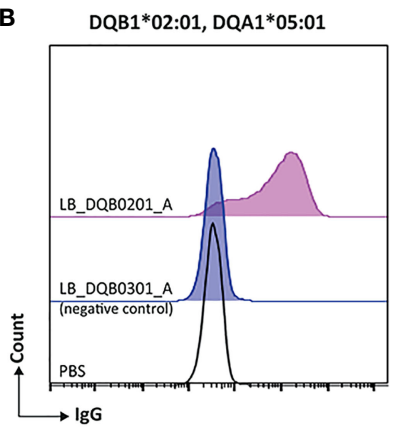

C DQB1*03:01, DQA1*06:01

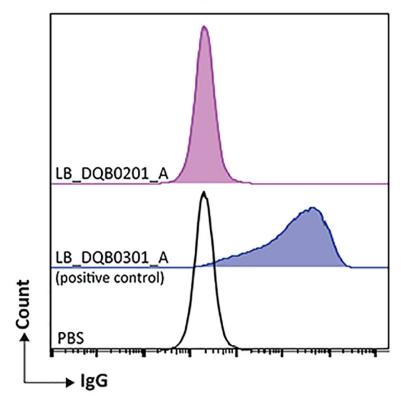

D

DQB1*02:01, DQA1*05:01

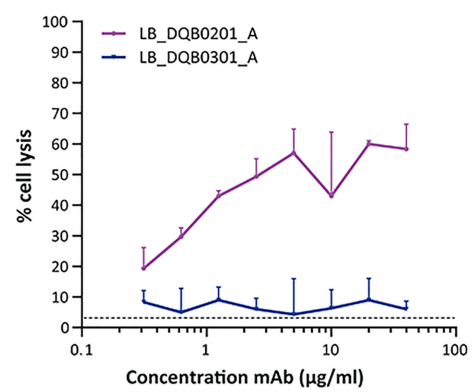

E

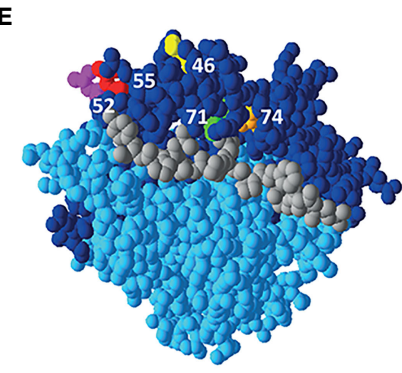

$\mathbf{F}$

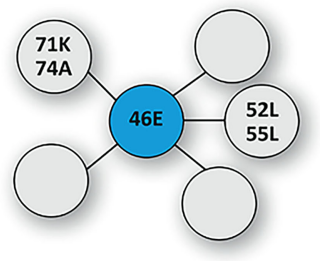

G

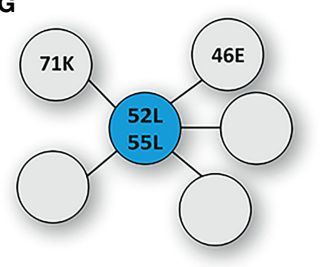

H

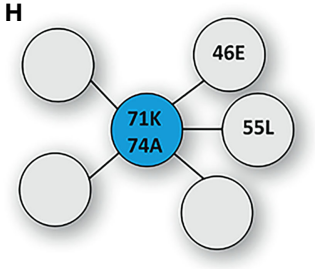

FIGURE 1 | Reactivity analysis of monoclonal antibody LB_DQB0201_A. (A) Comparison of the amino acid positions of interest of the HLA-DQB1 alleles on the reactive beads in the single antigen bead assay and a selection of the non-reactive HLA-DQB1 alleles. Flow cytometry crossmatches on EBV-LCLs expressing DQB1*02:01 (B) and DQB1*03:01 (C) showed that LB_DQB0201_A binds to natively expressed DQB1*02:01, but not to DQB1*03:01. (D) LB_DQB0201_A induced complement dependent cell lysis in a dose-dependent manner for cells expressing DQB1 ${ }^{*} 02: 01$. (E) Locations of amino acid 46E (yellow), 52L (magenta), $55 \mathrm{~L}$ (red), 71K (green) and 74A (orange) are indicated on the crystal structure of DQB1*02:01/DQA1*05:01 (PBD: 1S9V). The $\beta$ chain is depicted in dark blue, the $\alpha$ chain in light blue, and the peptide in grey. (F) Schematic representation of the antibody-footprint of LB_DQB0201_A with 46E or (G) 52L+55L or (H) 71K+74A as the functional epitope (cyan) with additional AA configurations (grey). Monoclonal antibody concentrations used for testing were $20 \mu \mathrm{g} / \mathrm{ml}$ for single antigen bead assay and FC-XM and $0.3125-0.625-1.25-2.5-5-10-20-40 \mu \mathrm{g} / \mathrm{ml}$ for CDC. BCM, background corrected mean fluorescence intensity; FC-XM, flowcytometric crossmatch; CDC, complement dependent cytotoxicity; PBS, phosphate-buffered saline; mAb, monoclonal antibody; EBV-LCL, Epstein-Barr Virus-transformed lymphoblastoid B-cell line; PBD, Protein Data Bank. 


\section{A}

LB_DQB0301_A

\begin{tabular}{lclcccc}
\hline HLA Allele & BCM & FC-XM & CDC & 45 & 46 & 47 \\
\hline DQB1*03:01/DQA1*03:01 & 19246 & & & E & V & Y \\
DQB1*03:01/DQA1*03:02 & 19050 & & & E & V & Y \\
DQB1*03:01/DQA1*05:01 & 17635 & & & E & V & Y \\
DQB1*03:01/DQA1*06:01 & 16132 & Positive & Positive & E & V & Y \\
DQB1*02:02/DQA1*05:01 & -111 & & & G & E & F \\
DQB1*02:01/DQA1*02:01 & -147 & Negative & Negative & G & E & F \\
DQB1*03:02/DQA1*03:02 & -149 & & & G & V & Y \\
DQB1*03:02/DQA1*03:01 & -156 & & & G & V & Y \\
DQB1*04:02/DQA1*03:01 & -160 & & & G & V & Y \\
DQB1*05:01/DQA1*01:01 & -181 & & & G & V & Y \\
DQB1*04:02/DQA1*06:01 & -197 & & & G & V & Y \\
DQB1*03:03/DQA1*02:01 & n/a & Negative & Negative & G & V & Y \\
Other DQ beads & $\leq 0$ & & & G & E/V & F/Y \\
\hline
\end{tabular}

B

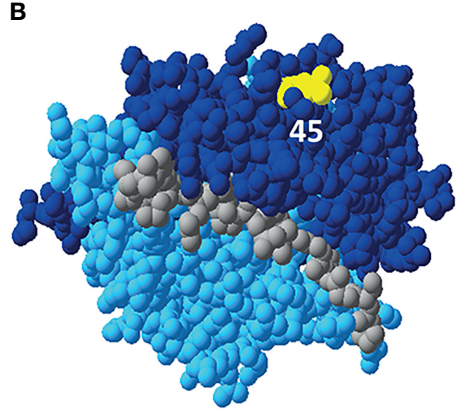

c

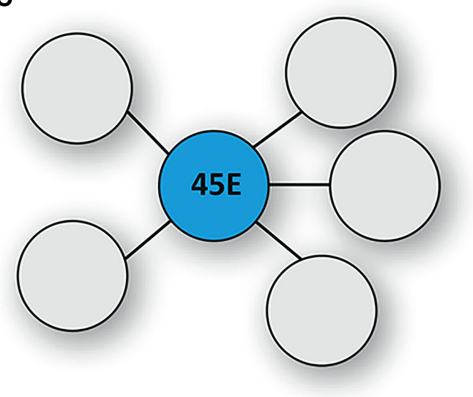

FIGURE 2 | Reactivity analysis of monoclonal antibody LB_DQB0301_A. (A) Comparison of the amino acid positions of interest of the HLA-DQB1 alleles on the reactive beads in the single antigen bead assay and a selection of the nonreactive HLA-DQB1 alleles. (B) Location of amino acid $45 E$ (yellow) is indicated on the crystal structure of DQB1*03:02/DQA1*03:01 (PBD: 4Z7U). The $\beta$ chain is depicted in dark blue, the $\alpha$ chain in light blue, and the peptide in grey. (C) Schematic representation of the antibody-footprint of LB_DQB0301_A interacting with the functional epitope 45E (cyan). BCM, background corrected mean fluorescence intensity; FC-XM, flowcytometric crossmatch; CDC, complement dependent cytotoxicity; PBD, Protein Data Bank.

$\mathrm{DQB} 1{ }^{\star} 03: 01, \mathrm{DQB} 1{ }^{\star} 03: 02, \mathrm{DQB} 1^{\star} 03: 03, \mathrm{DQB} 1^{\star} 04: 01$ and $\mathrm{DQB} 1{ }^{\star} 04: 02$ in the $\mathrm{SAB}$ assay (Figure $\mathbf{3 A}$ ). These alleles uniquely share 10 residues, namely $\mathrm{L}$ on position 53 , glutamine (Q) on position $84, \mathrm{~L}$ on position $85, \mathrm{E}$ on position $86, \mathrm{~L}$ on position 87 , threonine $(\mathrm{T})$ on position 89 , $\mathrm{T}$ on position 90 , A on position 125 , histidine $(\mathrm{H})$ on position 220 and $\mathrm{H}$ on position 221. Six of these AAs are present within eplet 84QL (84Q 86E 87L $89 \mathrm{~T} 90 \mathrm{~T} 125 \mathrm{~A}$ ), which also was one of the eplets identified by HLAMatchmaker to be solely present on the reactive HLADQB1 alleles. However, the residues constituting eplet 84QL exceed the $3.5 \AA$ radius and therefore cannot form a single eplet. Interestingly, eplet $125 \mathrm{AQ}$ was also identified, but this configuration is not further specified in HLAMatchmaker and is not present in the Epitope Registry either. Because of the relatively high number of uniquely shared residues and the positions of the AAs involved (Figures 3B, C), there are many different possible configurations of the functional epitope of LB_DQB0303_A. Without additional data on the actual interaction between LB_DQB0303_A antibody and the HLA molecule it is not possible to define the functional epitope that triggered the antibody response.

\section{Reactivity Analysis of mAb LB_DQB0303_B}

The mAb LB_DQB0303_B was generated from the same individual as LB_DQB0303_A, but showed a more restricted reactivity pattern against $\mathrm{DQB} 1^{\star} 03: 01, \mathrm{DQB} 1^{\star} 03: 02$, $\mathrm{DQB1}{ }^{\star}$ 03:03, $\mathrm{DQB1} 1^{\star} 04: 01$ and $\mathrm{DQB} 1^{\star} 04: 02$ (Figure 4A). The uniquely shared AA residues of these HLA-DQB1 alleles are T on position 140 and asparagine $(\mathrm{N})$ on position 182, of which the latter was also identified by HLAMatchmaker. Interestingly, HLAMatchmaker also identified 52PL (52P 53L); an eplet that is not present anymore in the current version of the HLA Epitope Registry. Although neither 52P nor 53L are uniquely shared between DQ3 and DQ4, and 52P is present on the antibody producer's HLA, the combination of $52 \mathrm{P}$ and $53 \mathrm{~L}$ is indeed uniquely shared by the reactive HLA-DQB1 alleles. While residues $52 \mathrm{P}$ and $53 \mathrm{~L}$ are located within a $3.5 \AA$ radius on top of the $\mathrm{DQB1} 1^{\star}$ 03:02/DQA1 ${ }^{\star} 03: 01$ molecule, residues $140 \mathrm{~T}$ and 


\section{A}

\begin{tabular}{|c|c|c|c|c|c|c|c|c|c|c|c|c|c|}
\hline HLA Allele & $\mathrm{BCM}$ & FC-XM & $\operatorname{CDC}$ & 53 & 84 & 85 & 86 & 87 & 89 & 90 & 125 & 220 & 221 \\
\hline DQB1*03:03/DQA1*02:01 & $\mathrm{n} / \mathrm{a}$ & Positive & Positive & $\mathrm{L}$ & $Q$ & $\mathrm{~L}$ & $\mathrm{E}$ & $\mathrm{L}$ & $T$ & $\begin{array}{c}\mathrm{T} \\
\mathrm{T}\end{array}$ & A & $\mathrm{H}$ & $\mathrm{H}$ \\
\hline DQB1*03:02/DQA1*02:01 & 17687 & & & $\mathrm{i}$ & $\hat{a}$ & $\mathrm{~L}$ & $\mathrm{E}$ & $\mathrm{i}$ & $T$ & $\mathrm{~T}$ & A & H & $\mathrm{H}$ \\
\hline DQB1*04:01/DQA1*02:01 & 17510 & & & $\mathrm{i}$ & 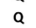 & $\mathrm{i}$ & $\mathrm{E}$ & $\mathrm{i}$ & $T$ & $T$ & A & H & $\mathrm{H}$ \\
\hline DQB1*03:01/DQA1*03:02 & 17040 & & & $\mathrm{i}$ & $a$ & $\mathrm{~L}$ & $\mathrm{E}$ & $\mathrm{i}$ & $T$ & $T$ & A & H & $\mathrm{H}$ \\
\hline DQB1*03:01/DQA1*03:01 & 16789 & & & $\mathrm{~L}$ & Q & $\mathrm{L}$ & $\mathrm{E}$ & $\mathrm{L}$ & $T$ & $T$ & A & H & $\mathrm{H}$ \\
\hline DQB1*03:02/DQA1*03:01 & 16676 & & & $\mathrm{i}$ & $a$ & $\mathrm{~L}$ & E & $\mathrm{i}$ & $T$ & $\mathrm{~T}$ & A & H & $\mathrm{H}$ \\
\hline DQB1*03:03/DQA1*03:02 & 16470 & & & $\mathrm{i}$ & $a$ & $\mathrm{~L}$ & E & $\mathrm{i}$ & $T$ & $T$ & A & H & $\mathrm{H}$ \\
\hline DQB1*04:02/DQA1*06:01 & 15936 & & & $\mathrm{i}$ & 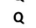 & $\mathrm{L}$ & $\mathrm{E}$ & $\mathrm{i}$ & $T$ & $T$ & A & H & $\mathrm{H}$ \\
\hline DQB1*03:01/DQA1*05:01 & 15736 & & & $\mathrm{~L}$ & $\hat{Q}$ & $\mathrm{~L}$ & $\mathrm{E}$ & $\mathrm{L}$ & $T$ & $T$ & A & H & $\mathrm{H}$ \\
\hline DQB1*03:03/DQA1*04:01 & 15709 & & & $\mathrm{~L}$ & $\hat{Q}$ & $\mathrm{~L}$ & $\mathrm{E}$ & $\mathrm{L}$ & $T$ & $T$ & A & H & $\mathrm{H}$ \\
\hline DQB1 ${ }^{*} 04: 02 / D Q A 1 * 03: 01$ & 15646 & & & $\mathrm{i}$ & $\hat{a}$ & $\mathrm{~L}$ & E & $\mathrm{i}$ & $T$ & $T$ & A & H & $\mathrm{H}$ \\
\hline DQB1 $1^{*} 04: 02 / D Q A 1 * 04: 01$ & 15148 & Positive & & $\mathrm{L}$ & $\hat{Q}$ & $\mathrm{~L}$ & E & $\mathrm{i}$ & $T$ & $T$ & A & H & $\mathrm{H}$ \\
\hline DQB1*04:01/DQA1*04:01 & 15100 & & & $\mathrm{~L}$ & $\hat{Q}$ & $\mathrm{~L}$ & $\mathrm{E}$ & $\mathrm{L}$ & $T$ & $T$ & A & H & $\mathrm{H}$ \\
\hline DQB1 ${ }^{*} 03: 02 / D Q A 1 * 03: 02$ & 14328 & & & $\mathrm{~L}$ & $\hat{Q}$ & $\mathrm{~L}$ & $\mathrm{E}$ & $\mathrm{L}$ & $T$ & $T$ & A & H & $\mathrm{H}$ \\
\hline DQB1*04:01/DQA1*05:01 & 14033 & & & $\mathrm{~L}$ & $\hat{Q}$ & $\mathrm{~L}$ & E & $\mathrm{L}$ & $T$ & $T$ & A & H & $\mathrm{H}$ \\
\hline DQB1*03:03/DQA1*06:01 & 13877 & & & $\mathrm{~L}$ & $\hat{Q}$ & $\mathrm{~L}$ & $\mathrm{E}$ & $\mathrm{i}$ & $T$ & $T$ & A & H & $\mathrm{H}$ \\
\hline DQB1 ${ }^{*} 03: 01 / D Q A 1 * 06: 01$ & 13731 & Positive & & $\mathrm{L}$ & $\hat{Q}$ & $\mathrm{~L}$ & E & $\mathrm{L}$ & $T$ & $T$ & A & H & $\mathrm{H}$ \\
\hline DQB1 ${ }^{*} 02: 01 / D Q A 1 * 02: 01$ & 13577 & Positive & & $\mathrm{L}$ & $\hat{Q}$ & $\mathrm{~L}$ & $\mathrm{E}$ & $\mathrm{L}$ & $T$ & $T$ & A & H & $\mathrm{H}$ \\
\hline DQB1*02:02/DQA1*02:01 & 13120 & & & $\mathrm{~L}$ & 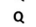 & $\mathrm{L}$ & $\mathrm{E}$ & $\mathrm{L}$ & $T$ & $T$ & A & H & $\mathrm{H}$ \\
\hline$D Q B 1{ }^{*} 02: 02 / D Q A 1 * 03: 02$ & 12094 & & & $\mathrm{~L}$ & $\hat{Q}$ & $\mathrm{~L}$ & $\mathrm{E}$ & $\mathrm{L}$ & $T$ & $T$ & A & H & $\mathrm{H}$ \\
\hline DQB1*02:02/DQA1*05:01 & 10352 & & & $\mathrm{~L}$ & $\hat{Q}$ & $\mathrm{~L}$ & E & $\mathrm{L}$ & $T$ & $T$ & A & H & $\mathrm{H}$ \\
\hline DQB1*02:01/DQA1*05:01 & 8184 & & & $\mathrm{~L}$ & $\hat{Q}$ & $\mathrm{~L}$ & $\mathrm{E}$ & $\mathrm{L}$ & $T$ & $T$ & A & H & $\mathrm{H}$ \\
\hline DQB1 ${ }^{*} 06: 03 / D Q A 1 * 01: 03$ & -90 & Negative & Negative & $Q$ & $E$ & $\mathrm{v}$ & A & $\mathrm{F}$ & $\mathrm{G}$ & i & G & $\mathrm{R}$ & $a$ \\
\hline DQB1 ${ }^{*} 06: 02 / D Q A 1 * 01: 02$ & -102 & & & a & E & $\mathrm{v}$ & A & $\mathrm{F}$ & $\mathrm{G}$ & i & G & $\mathrm{R}$ & $a$ \\
\hline DQB1*05:01/DQA1*01:02 & -117 & & & $\hat{a}$ & E & $\mathrm{v}$ & A & y & $\mathrm{G}$ & i & s & $\mathrm{R}$ & a \\
\hline DQB1 ${ }^{*} 06: 01 / D Q A 1{ }^{*} 02: 01$ & -128 & & & $\hat{Q}$ & E & $\mathrm{v}$ & A & $\mathrm{F}$ & $G$ & 1 & $\mathrm{G}$ & R & a \\
\hline Other $D Q$ beads & $\leq 0$ & & & $\hat{Q}$ & $\varepsilon$ & $\mathrm{v}$ & $\mathrm{A} / \mathrm{G}$ & $F / Y$ & $\mathrm{G}$ & i & $G / S$ & R & a \\
\hline
\end{tabular}

B

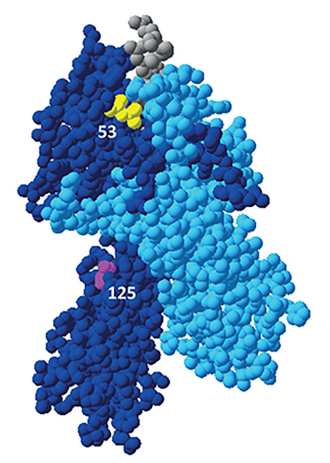

C

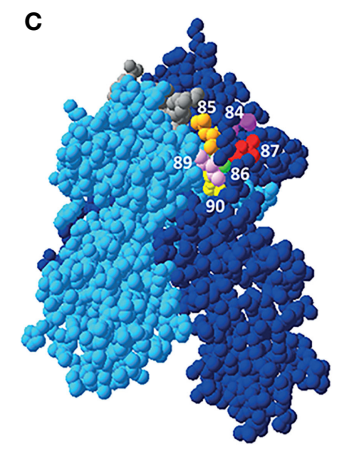

FIGURE 3 | Reactivity analysis of monoclonal antibody LB_DQB0303_A. (A) Comparison of the amino acid positions of interest of the HLA-DQB1 alleles on the reactive beads in the single antigen bead assay and a selection of the non-reactive HLA-DQB1 alleles. HLA-DQB1*03:03/DQA1*02:01 was not present in the single antigen bead panel. Locations of amino acid 53L (yellow), 125A (magenta) (B) and 84Q (magenta), 85L (orange), 86E (green), 87L (red), 89T (pink) and 90T (yellow) (C) are indicated on the crystal structure of DQB1*03:02/DQA1*03:01 (PBD: 4Z7U). The position of residues $220 \mathrm{H}$ and $221 \mathrm{H}$ could not be determined, as these AAs are not included in the crystal structure. The $\beta$ chain is depicted in dark blue, the $\alpha$ chain in light blue, and the peptide in grey. BCM, background corrected mean fluorescence intensity; FC-XM, flowcytometric crossmatch; CDC, complement dependent cytotoxicity; PBD, Protein Data Bank.

$182 \mathrm{~N}$ are located near the transmembrane region and are too far apart to form either a functional or structural epitope together (Figures 4B-E). Hence, mAb LB_DQB0303_B is specific for one of three possible functional epitopes; $52 \mathrm{P}+53 \mathrm{~L}$, or $140 \mathrm{~T}$, or $182 \mathrm{~N}$.

\section{Reactivity Analysis of mAb LB_DQB0303_C}

The mAb LB_DQB0303_C was reactive against $\mathrm{DQB1}^{\star} 03: 01$, $\mathrm{DQB}^{\star}{ }^{\star} 03: 02$ and $\mathrm{DQB} 1^{\star} 03: 03$, demonstrating a more narrow reactivity pattern than $\mathrm{mAbs}$ LB_DQB0303_A and LB_DQB0303_B, which were generated from the same individual (Figure 5A). The $\mathrm{DQB1}{ }^{\star} 03$ alleles share residue proline $(\mathrm{P})$ on position 55 , which is located on top of the DQB1 ${ }^{\star} 03: 02 / D Q A 1{ }^{\star} 03: 01$ molecule (Figure 5B) and is the functional epitope of LB_DQB0303_C (Figure 5C). Residue $55 \mathrm{P}$ is part of eplet 55PP (55P 56P) which was identified by HLAMatchmaker and also includes residue 56P. This residue is not a mismatched amino acid for the antibody producer and is also present on non-reactive HLA-DQB1 alleles. However, it is not possible to determine whether or not $56 \mathrm{P}$ is crucial for antibody induction. Therefore, we cannot rule out that $56 \mathrm{P}$ is part of the eplet and we conclude that mAb LB_DQB0303_C supports the antibody verification of eplet 55PP.

\section{Reactivity Analysis of mAbs LB_DQB0402_A, LB_DQB0601_B and LB_DQB0602_B}

The mAbs LB_DQB0402 and LB_DQB0601_B were generated from the same individual using HLA-DQB1*04:02 and HLADQB1*06:01 monomers, respectively, and showed similar reactivity patterns against $\mathrm{HLA}$ alleles $\mathrm{DQB} 1^{\star} 04: 01$, $\mathrm{DQB} 1^{\star} 04: 02, \mathrm{DQB} 1{ }^{\star} 05: 01, \mathrm{DQB} 1^{\star} 05: 02, \mathrm{DQB} 1{ }^{\star} 05: 03$, $\mathrm{DQB1} 1^{\star 06: 01, D Q B 1}{ }^{\star} 06: 02, \mathrm{DQB} 1^{\star} 06: 03$ and $\mathrm{DQB} 1^{\star} 06: 04$ in SAB analysis (Figures 6A, B). LB_DQB0602_B was generated from a different individual with a $\mathrm{HLA}_{-\mathrm{DQB}}{ }^{\star} 06: 02$ monomer but showed the same reactivity pattern (Supplementary Figure 4). The HLA-DQB1 alleles recognized by these three 
A

\begin{tabular}{|c|c|c|c|c|c|c|c|}
\hline HLA Allele & $\mathrm{BCM}$ & FC-XM & $\operatorname{CDC}$ & 52 & 53 & 140 & 182 \\
\hline DQB1*03:03/DQA1*02:01 & $n / a$ & Positive & Positive & $P$ & $\mathrm{~L}$ & $T$ & $\mathbf{N}$ \\
\hline DQB1*03:02/DQA1*02:01 & 18953 & & & $\mathbf{P}$ & $\mathrm{L}$ & $\mathrm{T}$ & $\mathbf{N}$ \\
\hline DQB1*03:03/DQA1*03:02 & 18507 & & & $P$ & $\mathrm{~L}$ & $\mathrm{~T}$ & $\mathbf{N}$ \\
\hline DQB1*03:02/DQA1*03:01 & 17980 & & & $\mathbf{P}$ & L & 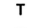 & $\mathbf{N}$ \\
\hline DQB1*03:01/DQA1*03:02 & 17720 & & & $\mathbf{P}$ & L & $T$ & N \\
\hline DQB1*03:03/DQA1*04:01 & 17552 & & & $\mathbf{P}$ & L & $T$ & $\mathbf{N}$ \\
\hline DQB1*03:01/DQA1*03:01 & 17218 & & & $\mathbf{P}$ & L & T & $\mathrm{N}$ \\
\hline DQB1*03:01/DQA1*05:01 & 17092 & & & $P$ & L & $\mathrm{T}$ & $\mathbf{N}$ \\
\hline DQB1*03:02/DQA1*03:02 & 16490 & & & $\mathbf{P}$ & $\mathrm{L}$ & T & $\mathbf{N}$ \\
\hline DQB1*03:03/DQA1*06:01 & 15967 & & & $\mathbf{P}$ & $\mathrm{L}$ & $\mathrm{T}$ & $\mathrm{N}$ \\
\hline DQB1*03:01/DQA1*06:01 & 15048 & Positive & & $\mathbf{P}$ & $\mathrm{L}$ & $\mathrm{T}$ & $\mathbf{N}$ \\
\hline DQB1*04:01/DQA1*02:01 & 14148 & & & $\mathbf{P}$ & $\mathrm{L}$ & $\mathrm{T}$ & $\mathbf{N}$ \\
\hline DQB1*04:02/DQA1*04:01 & 11557 & Positive & & $\mathbf{P}$ & L & T & $\mathrm{N}$ \\
\hline DQB1*04:02/DQA1*03:01 & 9714 & & & $\mathbf{P}$ & L & $T$ & $\mathbf{N}$ \\
\hline DQB1*04:02/DQA1*06:01 & 9316 & & & $\mathbf{P}$ & L & T & $\mathbf{N}$ \\
\hline DQB1*04:01/DQA1*04:01 & 9220 & & & $\mathbf{P}$ & $\mathrm{L}$ & $T$ & $\mathbf{N}$ \\
\hline DQB1*04:01/DQA1*05:01 & 7984 & & & $\mathbf{P}$ & $\mathrm{L}$ & T & $\mathrm{N}$ \\
\hline DQB1*02:02/DQA1*02:01 & -77 & & & $\mathrm{~L}$ & $\mathrm{~L}$ & A & $\mathrm{s}$ \\
\hline DQB1*02:01/DQA1*05:01 & -82 & & & $\mathrm{~L}$ & $\mathrm{~L}$ & A & $\mathrm{s}$ \\
\hline $\mathrm{DQB1}{ }^{*} 02: 01 / \mathrm{DQA} 1 * 02: 01$ & -89 & & & L & L & A & $\mathrm{s}$ \\
\hline $\mathrm{DQB1} * 02: 02 / \mathrm{DQA} 1 * 03: 02$ & -102 & & & $\mathrm{~L}$ & L & A & $\mathrm{s}$ \\
\hline DQB1*06:02/DQA1*01:02 & -102 & & & $\mathrm{P}$ & a & A & $\mathrm{s}$ \\
\hline DQB1*02:02/DQA1*05:01 & -103 & & & $\mathrm{~L}$ & $\mathrm{~L}$ & A & s \\
\hline DQB1*06:03/DQA1*01:03 & -117 & Negative & Negative & $\mathrm{P}$ & a & A & $\mathrm{s}$ \\
\hline Other $D Q$ beads & $\leq 0$ & & & $P$ & a & A & $\mathrm{s}$ \\
\hline
\end{tabular}

C

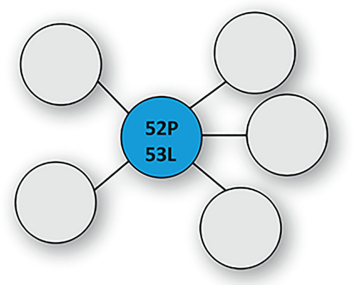

D

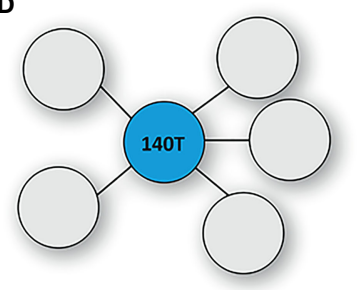

B

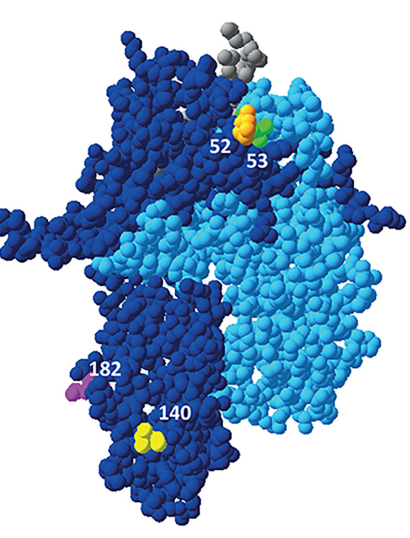

E

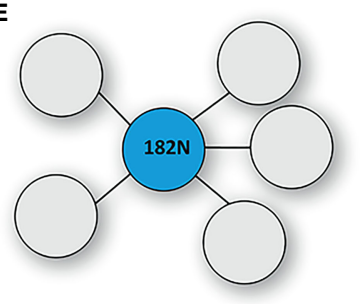

FIGURE 4 | Reactivity analysis of monoclonal antibody LB_DQB0303_B. (A) Comparison of the amino acid positions of interest of the HLA-DQB1 alleles on the reactive beads in the single antigen bead assay and a selection of the nonreactive HLA-DQB1 alleles. HLA-DQB1 ${ }^{*} 03: 03 / D Q A 1{ }^{*} 02: 01$ was not present in the single antigen bead panel. (B) Locations of amino acid 52L (orange), 53L (green), 140T (yellow) and 182N are indicated on the crystal structure of DQB1*03:02/ DQA1*03:01 (PBD: 4Z7U). The $\beta$ chain is depicted in dark blue, the $\alpha$ chain in light blue, and the peptide in grey. (C) Schematic representation of the antibody footprint of LB_DQB0303_B interacting with 52P+53L, or 140T (D) or 182N (E) as the functional epitope (cyan). BCM, background corrected mean fluorescence intensity; FC-XM, flowcytometric crossmatch; CDC, complement dependent cytotoxicity; PBD, Protein Data Bank.

mAbs all shared arginine $(\mathrm{R})$ on position 55. Interestingly, LB_DQB0601_B showed stronger binding for HLA antigens with $53 \mathrm{Q}$, which is not only illustrated by higher mean fluorescence intensity (MFI) in SAB analysis, but also by the FACS-XM and CDC results. FACS-XM of LB_DQB0601_B with EBV-LCLs carrying DQB1 ${ }^{\star} 06: 03$, an allele that bears $53 \mathrm{Q}$, showed a significantly higher MFI than with DQB1*04:02carrying cells that lack this residue (Figures 6C, D). Accordingly, cell lysis by LB_DQB0601_B was also substantially lower in CDC assays with cells expressing DQB1 ${ }^{\star} 04: 02$ than DQB1*06:03-expressing cells (Figures 6E and Supplementary Figure 3D). This difference in binding strength and cytotoxicity was not observed for mAbs LB_DQB0402_A and LB_DQB0602_B (Figures 6C-E and Supplementary Figure 3D) and could not be explained by the alpha chain of the HLA-DQ molecules. As 55R is uniquely shared by all reactive HLA-DQB1 alleles, we consider this residue as the functional epitope for mAbs LB_DQB0402_A and LB_DQB0602_B (Figures 6F, G), which further supports the already antibody-verified eplet 55R in the HLA Epitope Registry. Surprisingly, this nor any other eplet was identified by HLAMatchmaker. Although residue 53Q, which is located within a $3.5 \AA$ distance of 55R, is not crucial for antibody binding, it evidently affects the binding strength of $\mathrm{mAb}$ LB_DQB0601_B (Figures 6F, H). Whether residue 53Q is part of the functional epitope for mAb LB_DQB0601_B is yet to be determined.

\section{DISCUSSION}

In this study, we generated 15 recombinant human HLA-DQ specific mAbs with six distinct specificities through isolation of memory B cells from immunized individuals using biotinylated soluble HLA-DQ monomers. Whereas previously HLA tetramers were used for memory B cell isolation, this study shows that also monomeric HLA molecules can be used for HLA-specific memory B cell isolation. Although antibodies specific for the HLA-DQ alpha chain (DQA1) have been described $(32,44,45)$, analysis of $\mathrm{SAB}$ assay reactivity patterns demonstrated that all $\mathrm{mAbs}$ were only specific for the HLA-DQ beta chain (DQB1). This is likely to be explained by the HLA-DQ 
A

LB_DQB0303_C

\begin{tabular}{|c|c|c|c|c|c|}
\hline HLA Allele & BCM & FC-XM & CDC & 55 & 56 \\
\hline DQB1*03:03/DQA1*02:01 & $n / a$ & Positive & Positive & $P$ & $P$ \\
\hline DQB1*03:02/DQA1*02:01 & 19679 & & & $\mathbf{P}$ & $\mathrm{P}$ \\
\hline DQB1*03:01/DQA1*05:01 & 18494 & & & $\mathbf{P}$ & $\mathrm{P}$ \\
\hline DQB1*03:03/DQA1*03:02 & 18434 & & & $\mathbf{P}$ & $\mathrm{P}$ \\
\hline DQB1*03:02/DQA1*03:02 & 18265 & & & $\mathbf{P}$ & $\mathrm{P}$ \\
\hline DQB1*03:01/DQA1*03:01 & 17999 & & & $\mathbf{P}$ & $\mathrm{P}$ \\
\hline DQB1*03:03/DQA1*06:01 & 17780 & & & $\mathbf{P}$ & $\mathrm{P}$ \\
\hline DQB1*03:02/DQA1*03:01 & 17719 & & & $\mathbf{P}$ & $\mathrm{P}$ \\
\hline DQB1*03:03/DQA1*04:01 & 17442 & & & $\mathbf{P}$ & $\mathrm{P}$ \\
\hline DQB1*03:01/DQA1*06:01 & 17121 & Positive & Positive & $\mathbf{P}$ & $\mathrm{P}$ \\
\hline DQB1*03:01/DQA1*03:02 & 17114 & & & $\mathbf{P}$ & $\mathrm{P}$ \\
\hline DQB1*06:03/DQA1*01:03 & -77 & & & $\mathrm{R}$ & $\mathrm{P}$ \\
\hline DQB1*04:02/DQA1*03:01 & -110 & & & $\mathrm{R}$ & L \\
\hline DQB1*04:02/DQA1*06:01 & -112 & & & $\mathrm{R}$ & L \\
\hline DQB1*06:02/DQA1*01:02 & -117 & & & $\mathrm{R}$ & $\mathrm{P}$ \\
\hline DQB1*02:02/DQA1*03:02 & -122 & & & $\mathrm{~L}$ & $\mathrm{P}$ \\
\hline DQB1*02:01/DQA $1 * 05: 01$ & -127 & Negative & Negative & $\mathrm{L}$ & $\mathrm{P}$ \\
\hline DQB1*02:01/DQA1*02:01 & -134 & & & $\mathrm{~L}$ & $\mathrm{P}$ \\
\hline DQB1*05:01/DQA1*01:01 & -143 & & & $\mathrm{R}$ & $\mathrm{P}$ \\
\hline DQB1*04:01/DQA1*04:01 & -145 & & & $\mathrm{R}$ & L \\
\hline Other DQ beads & $\leq 0$ & & & $L / R$ & $L / P$ \\
\hline
\end{tabular}

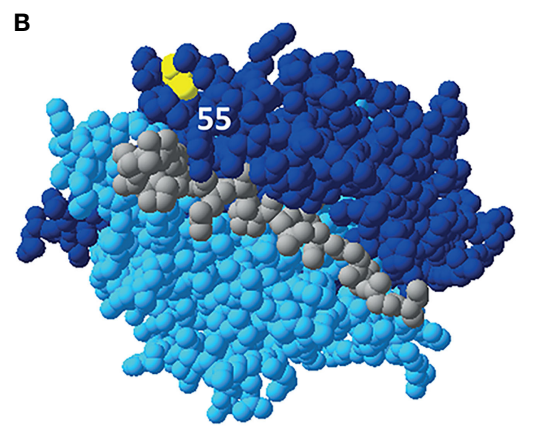

C

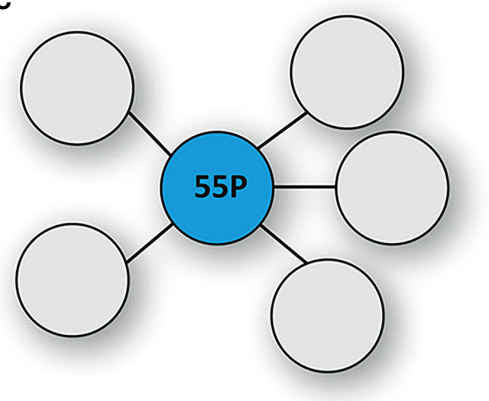

FIGURE 5 | Reactivity analysis of monoclonal antibody LB_DQB0303_C. (A) Comparison of the amino acid positions of interest of the HLA-DQB1 alleles on the reactive beads in the single antigen bead assay and a selection of the nonreactive HLA-DQB1 alleles. HLA-DQB1*03:03/DQA1*02:01 was not present in the single antigen bead panel. (B) Location of amino acid 55P (yellow) is indicated on the crystal structure of DQB1*03:02/DQA1*03:01 (PBD: 4Z7U). The $\beta$ chain is depicted in dark blue, the $\alpha$ chain in light blue, and the peptide in grey. (C) Schematic representation of the antibody footprint of LB_DQB0303_C interacting with 55P as the functional epitope (cyan). BCM, background corrected mean fluorescence intensity; FC-XM, flowcytometric crossmatch; CDC, complement dependent cytotoxicity; PBD, Protein Data Bank.

monomers used for isolation, which contained HLA-DQA1 alleles that did not correspond to any of the immunizing alleles of our subjects. Since only mismatched eplets on the alpha or beta chain of the donor HLA induce the formation of antibodies directed towards HLA alleles bearing that particular eplet (10), it is not surprising that only HLA-DQB1-specific memory B cells were sorted. While our generated mAbs are directed against HLA-DQB1 only, it has been previously described that structural epitopes on HLA-DQ molecules can cover both the alpha and beta chain $(44,46)$. Additionally, DSA specific for a particular combination of HLA-DQA1 and HLA-
DQB1 have been reported, suggesting that the functional epitope and/or any additional crucial configurations can consist of residues on both chains (47). Reactivity pattern analysis of the mAbs was limited due to the restricted number of HLA-DQA1/ HLA-DQB1 combinations in the SAB assay. Additional testing of the $m A b s$ in a SAB assay from another vendor (One Lambda) would expand the number of HLA-DQA1/HLA-DQB1 combinations tested. However, since it is unlikely that the mAbs presented here are specific for the HLA-DQA1/HLADQB1 combination, as all beads containing a particular HLADQB1 allele were positive regardless of the HLA-DQA1 allele, 


\begin{tabular}{|c|c|c|c|c|c|}
\hline HLA Allele & $\mathrm{BCM}$ & FC-XM & CDC & 53 & 55 \\
\hline DQB1*04:01/DQA1*02:01 & 19597 & & & $\mathrm{~L}$ & \\
\hline DQB1*06:02/DQA1*01:02 & 19492 & & & $Q$ & $\mathbf{R}$ \\
\hline DQB1*06:01/DQA1*01:03 & 18798 & & & $Q$ & $\mathrm{R}$ \\
\hline DQB1*06:04/DQA1*01:02 & 17938 & & & $Q$ & \\
\hline DQB1*04:02/DQA1*04:01 & 17811 & pos & pos & $\mathrm{L}$ & $\mathbf{R}$ \\
\hline $\mathrm{DQB1}^{*} 04: 02 / \mathrm{DQA1} 1^{*} 03: 01$ & 17432 & & & $\mathrm{~L}$ & \\
\hline DQB1*06:01/DQA1*01:04 & 17122 & & & $Q$ & $\mathbf{R}$ \\
\hline QB1*04:01/DQA1*05:01 & 17066 & & & $\mathrm{~L}$ & $\mathbf{R}$ \\
\hline DQB1*06:01/DQA1*02:01 & 16756 & & & a & $\mathrm{R}$ \\
\hline DQB1*04:02/DQA1*06:01 & 16745 & & & $\mathrm{~L}$ & $\mathbf{R}$ \\
\hline DQB1*06:03/DQA1*01:03 & 16672 & pos & & $Q$ & $\mathrm{R}$ \\
\hline DQB1*05:01/DQA1*01:02 & 15859 & & & Q & $\mathrm{R}$ \\
\hline DQB1*05:02/DQA1*01:02 & 14601 & & & $Q$ & $\mathbf{R}$ \\
\hline DQB1*04:01/DQA1*04:01 & 14533 & & & $\mathrm{~L}$ & $\mathrm{R}$ \\
\hline DQB1*05:01/DQA1*01:01 & 13142 & & & a & $\mathrm{R}$ \\
\hline DQB1*05:03/DQA1*01:04 & 12510 & & & $\hat{a}$ & $\mathrm{R}$ \\
\hline DQB1*02:01/DQA1*02:01 & -100 & & & L & $\mathrm{L}$ \\
\hline DQB1*03:01/DQA $* 03: 01$ & -120 & & & 1 & $\mathrm{P}$ \\
\hline $\mathrm{DQB1}{ }^{*} 03: 01 / \mathrm{DQA} 1 * 05: 01$ & -128 & & & $\mathrm{~L}$ & $\mathrm{p}$ \\
\hline DQB1*03:01/DQA1*06:01 & -137 & neg & neg & $\mathrm{L}$ & $\mathrm{p}$ \\
\hline $\mathrm{DQB1}{ }^{*} 03: 03 / \mathrm{DQA} 1^{*} 04: 01$ & -167 & & & L & P \\
\hline Other $D Q$ beads & $\leq 0$ & & & & \\
\hline
\end{tabular}

LB_DQB0402_A

LB_DQB0601_B

\begin{tabular}{|c|c|c|c|c|c|}
\hline HLA Allele & $\mathrm{BCM}$ & FC-XM & CDC & 53 & 55 \\
\hline$\overline{D Q B 1}{ }^{*} 06: 04 / \mathrm{DQA1}^{*} 01: 02$ & 18510 & & & $Q$ & $R$ \\
\hline DQB1 ${ }^{*} 06: 02 / \mathrm{DQA1}^{*} 01: 02$ & 18206 & & & $a$ & $\mathrm{R}$ \\
\hline DQB1*05:01/DQA $1 * 01: 02$ & 16388 & & & Q & $\mathrm{R}$ \\
\hline DQB1*06:01/DQA1*02:01 & 15755 & & & Q & $\mathrm{R}$ \\
\hline DQB1*06:01/DQA $1^{*} 01: 03$ & 15718 & & & Q & $\mathbf{R}$ \\
\hline DQB1*06:03/DQA $1^{*} 01: 03$ & 15107 & pos & pos & Q & $\mathbf{R}$ \\
\hline DQB1*05:01/DQA $1 * 01: 01$ & 14178 & & & Q & $\mathbf{R}$ \\
\hline DQB1 ${ }^{* 05}: 02 / \mathrm{DQAA}_{1}^{* 01: 02}$ & 13849 & & & Q & $\mathbf{R}$ \\
\hline DQB1*06:01/DQA $1^{*} 01: 04$ & 13336 & & & Q & $\mathbf{R}$ \\
\hline DQB1*05:03/DQA $1 * 01: 04$ & 12507 & & & Q & $\mathbf{R}$ \\
\hline DQB1 ${ }^{*} 04: 02 / \mathrm{DQA}_{1}{ }^{* 04: 01}$ & 4377 & pos & pos & $\mathrm{L}$ & $\mathrm{R}$ \\
\hline DQB1*04:01/DQA1*02:01 & 3750 & & & $\mathrm{~L}$ & $\mathrm{R}$ \\
\hline DQB1*04:01/DQA1*05:01 & 3255 & & & $\mathrm{~L}$ & $\mathbf{R}$ \\
\hline DQB1*04:01/DQA $1 * 04: 01$ & 1990 & & & $\mathrm{~L}$ & $\mathbf{R}$ \\
\hline DQB1*04:02/DQA $1 * 03: 01$ & 1816 & & & $\mathrm{~L}$ & $\mathbf{R}$ \\
\hline DQB1*04:02/DQA $1 * 06: 01$ & 1605 & & & $\mathrm{~L}$ & $\mathbf{R}$ \\
\hline DQB1*03:01/DQA1*03:01 & -105 & & & $\mathrm{~L}$ & $\mathrm{P}$ \\
\hline DQB1*03:01/DQA1*06:01 & -120 & neg & neg & $\mathrm{L}$ & $\mathrm{P}$ \\
\hline DQB1*02:01/DQA1*02:01 & -132 & & & $\mathrm{~L}$ & L \\
\hline DQB1*03:03/DQA1*04:01 & -142 & & & $L^{2}$ & $\mathrm{P}$ \\
\hline DQB1*03:01/DQA1*05:01 & -154 & & & $\mathrm{~L}$ & $\mathrm{P}$ \\
\hline Other DQ beads & $\leq 0$ & & & $\mathrm{~L}$ & \\
\hline
\end{tabular}

C

DQB1*06:03, DQA $1 * 01: 03$

D DQB1*04:02, DQA1*04:01

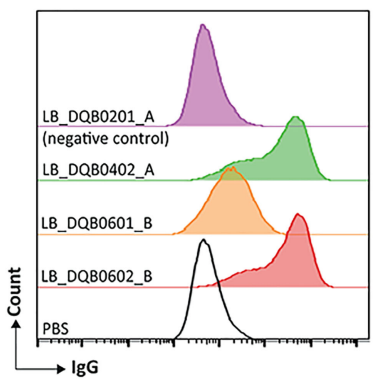

E

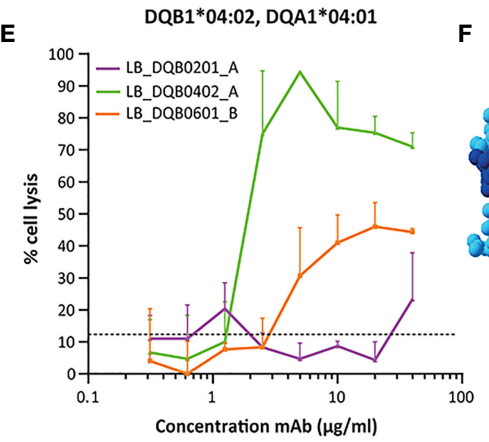

$\mathbf{F}$

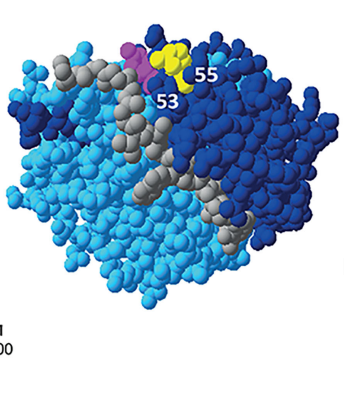

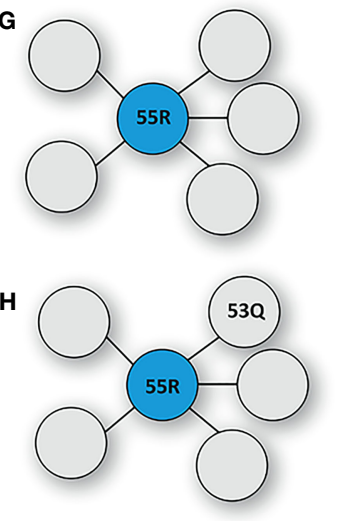

FIGURE 6 | Reactivity analysis of monoclonal antibodies LB_DQB0402_A and LB_DQB0601_B. (A) Comparison of the amino acid positions of interest of the HLADQB1 alleles on the reactive beads in the single antigen bead assay and a selection of the nonreactive HLA-DQB1 alleles for LB_DQB0402_A and LB_DQB0601_B (B). Flow cytometry crossmatches with EBV-LCLs showed a higher binding strength of mAb LB_DQB0601_B for DQB1*06:03-expressing cells (C) than DQB1*04:02-expressing cells (D). (E) LB_DQB0402_A induced a higher percentage of complement dependent cell lysis than LB_DQB0601_B for DQB1*04:02expressing cells. (F) Locations of amino acid 53Q (magenta) and 55R (yellow) are indicated on the crystal structure of DQB1*06:02/DQA1*01:02 (PBD: 1UVQ). The $\beta$ chain is depicted in dark blue, the $\alpha$ chain in light blue, and the peptide in grey. (G) Schematic representation of the footprint of mAbs LB_DQB0402_A and LB_DQB0602_B interacting with functional epitope 55R (cyan). (H) Schematic representation of the antibody footprint of LB_DQB0601_B that has a stronger binding to the functional epitope 55R (cyan) when additional amino acid 53Q (grey) is present. Monoclonal antibody concentrations used for testing were $20 \mathrm{\mu g} / \mathrm{ml}$ for single antigen bead assay and FC-XM and $0.3125-0.625-1.25-2.5-5-10-20-40 \mu \mathrm{g} / \mathrm{ml}$ for CDC. BCM, background corrected mean fluorescence intensity; FC-XM, flowcytometric crossmatch; CDC, complement dependent cytotoxicity; pos, positive; neg, negative; PBS, phosphate-buffered saline; mAb, monoclonal antibody; EBV-LCL, Epstein-Barr Virus-transformed lymphoblastoid B-cell line; PBD, Protein Data Bank. 
these analyses were not performed. Nonetheless, the proximity of HLA-DQA1 to several of the uniquely shared AAs on HLADQB1 does suggest that both chains could play a role in the structural epitopes recognized by the mAbs. Selection of patient samples that display serum reactivity specifically against HLADQA1 and the increasing availability of soluble HLA-DQ monomers will enhance the likelihood of generating mAbs directed against previously described HLA-DQA1 eplets (32, $44,45)$ or mAbs specific for a HLA-DQA1/HLA-DQB1 combination (47).

The original definition of an eplet resembles the functional epitope, which determines the antibody specificity through its interaction with the complementarity-determining region 3 of the heavy chain (CDR-H3) of the antibody $(11,48-50)$. In order to determine the functional epitopes of our generated mAbs, we used HLA-EMMA to identify uniquely shared AAs of the reactive HLA alleles which we then correlated to known eplets. Similar to the previously described analyses of HLA-DR specific mAbs (35), the analysis of mAbs LB_DQB0301_A and LB_DQB0303_C supported the antibody-verified status of eplet $45 \mathrm{EV}$ and eplet 55PP respectively.

For mAbs LB_DQB0201_A, LB_DQB0303_A and LB_DQB0303_B we observed multiple uniquely shared residues that were not in a $3.5 \AA$ radius. Therefore, we identified multiple potential functional epitopes that could have triggered the antibody response. It is evident that $\mathrm{SAB}$ reactivity analysis of the mAbs with HLA-EMMA resulted in a more extensive analysis of the possible functional epitopes than HLAMatchmaker. Furthermore, some of the eplets identified by HLAMatchmaker exceed the $3.5 \AA$ radius defining an eplet (11), a problem which was also previously addressed by Kramer et al. (35). Interestingly, an earlier version of the HLA Epitope Registry included eplets $45 \mathrm{GE}_{3}$ (45G46E47F 74A75V77R 52L53L55L56P57A), 84QL (84Q85L86E90T 53L 125A) and 52LP 3 (52P53L 140T 182N) (20), where the subscripted numbers indicated the possible numbers of epitopes that are shared within the same group of HLA-DQ antigens (20). We speculate that these former eplet definitions were removed from the currently available version of the HLA Epitope Registry website because they exceed the $3.5 \AA$ radius. However, these eplet definitions do resemble the reactivity patterns of our generated $\mathrm{mAbs}$ and possible include residues that contribute to the actual functional epitope. Additionally, mismatched AAs between the immunizer and antibody producer that were not uniquely shared between the reactive HLA alleles could still be a part of the functional epitope when they are located within $3.5 \AA$ of the uniquely shared residue.

For mAbs LB_DQB0402_A and LB_DQB0602_B, residue $55 \mathrm{R}$ was identified as the uniquely shared residue, which ensured the antibody-verification of eplet 55R with our more advanced methodology than the adsorption and elution study currently used for the verification of the eplet (32). Curiously, eplet 55R was not identified by HLAMatchmaker analysis, while this eplet is present in the HLA Epitope Registry. This issue of inaccuracy in eplet software has been previously addressed by Tassone et al. (51). As observed in the SAB data, 55R was also the uniquely shared residue for $\mathrm{mAb}$ LB_DQB0601_B, but this mAb demonstrated increased binding strength for eplet 55R with residue 53Q as additional configuration. Since binding and cytotoxicity still occurred in the absence of 53Q, it seems that 53Q is not a crucial AA configuration (18), a phenomenon that was previously described for a number of HLA-DR eplets (35). However, based on the location of the two residues, we cannot rule out that the actual functional epitope that induced the antibody response of LB_DQB0601_B mAb was the combination of residue 55R and 53Q.

Overall, in-depth analysis of luminex SAB data of HLA-specific mAbs can result in the identification of functional epitopes on HLA molecules. However, in some cases further studies of the interaction between antibody and HLA molecule is required to establish the functional epitope that determines the antibody specificity. In future studies, crystallography or cryogenic electron microscopy (cryo-EM) of the binding interface between mAbs and their target HLA will allow for precise localization of the involved residues that interact with the CDR-H3 of the $\mathrm{mAb}$ and will decipher the residues that comprise the functional epitope (52). Additionally, site-directed mutagenesis of HLA molecule targets can be used to deduce crucial AAs involved in antibody binding (53) similar as has been done in the past for HLA epitope mapping (54). However, the influence of AA substitution on surface potential has to be considered (55). Finally, testing mAbs LB_DQB0201_A, LB_DQB0303_A and LB_DQB0303_B against a larger panel of cells bearing less common HLA alleles, which are not included in the current SAB assays, could eliminate specific residues as the possible functional epitope, since there are several less common but 'well-documented' HLA-DQB1 alleles $(56,57)$ that contain only some, but not all residues of a reactivity pattern.

Eplet-based HLA matching could be an important step in preventing dnDSA formation and therefore improve graft outcomes after transplantation. Although it was not possible to determine one single functional epitope for several of the HLADQ specific mAbs, the reactivity patterns are still relevant and useful for matching strategies in clinical transplantation, because the uniquely shared AAs on the reactive HLA alleles are always present together on the alleles in the currently used SAB assays and other commonly observed HLA-DQB1 alleles $(56,57)$. The correct definition of eplets, which can be complex as becomes apparent from this investigation and previously performed analyses $(35,58)$, is crucial for studies that aim to define the immunogenicity of individual eplets, as such investigations will be biased if eplets that actually belong to the same reactivity pattern are considered as multiple separate eplets (59). Consideration of reactivity patterns that consist of multiple eplets or AAs is also of importance when the total eplet or AA mismatch load is used to determine immunological risk, since this method could result in an overestimation of the molecular mismatch when multiple eplet or AAs that belong to a single antibody induction are added up. Furthermore, we acknowledge that simply using the molecular mismatch load as a parameter for immunological risk does not provide a full picture, since dnDSA formation can already be induced by a single eplet or AA mismatch (17). Additionally, alternative algorithms considering physiochemical properties of AA mismatches (12) and the 
presence of T cell epitopes for indirect presentation (60) may also be of value in the assessment of the risk to develop humoral alloimmunity in the clinical setting.

Although experimental verification of theoretical HLA eplets using HLA-specific mAbs is a laborious endeavor, we consider this as the preferred method of verification of theoretical eplets over other methods such as serum analysis of immunized patients, due to the polyclonal nature of the circulating antibodies. Nevertheless, alternative approaches using clinical datasets can be complementary to the experimental verification of HLA eplets. In this respect, one of the aims of the $18^{\text {th }}$ International HLA and Immunogenetics workshop (https://www.ihiw18.org/) is the definition of immunogenic epitopes by analyzing a large dataset of single antigen bead data from non-sensitized first kidney transplant recipients. Since second-field HLA typing is available for these patients, antibody reactivity can be mapped to known eplets, prompting further experimental verification of these eplets.

To the best of our knowledge, this is the first study in which recombinant human HLA-DQ-specific mAbs were generated through isolation of memory $B$ cells from immunized individuals using biotinylated soluble HLA-DQ monomers. This unique set of mAbs is not only an excellent tool for indept analysis of HLA-DQ eplets, but also provides the opportunity to study the pathogenicity of HLA-DQ antibodies, which are the most prevalent alloantibodies in renal transplantation (4-9).

\section{DATA AVAILABILITY STATEMENT}

The raw data supporting the conclusions of this article will be made available by the authors, without undue reservation.

\section{REFERENCES}

1. Sellares J, de Freitas DG, Mengel M, Reeve J, Einecke G, Sis B, et al. Understanding the Causes of Kidney Transplant Failure: The Dominant Role of Antibody-Mediated Rejection and Nonadherence. Am J Transplant (2012) 12(2):388-99. doi: 10.1111/j.1600-6143.2011.03840.x

2. Einecke G, Sis B, Reeve J, Mengel M, Campbell PM, Hidalgo LG, et al. Antibody-Mediated Microcirculation Injury Is the Major Cause of Late Kidney Transplant Failure. Am J Transplant (2009) 9(11):2520-31. doi: 10.1111/j.1600-6143.2009.02799.x

3. El-Zoghby ZM, Stegall MD, Lager DJ, Kremers WK, Amer H, Gloor JM, et al. Identifying Specific Causes of Kidney Allograft Loss. Am J Transplant (2009) 9(3):527-35. doi: 10.1111/j.1600-6143.2008.02519.x

4. Willicombe M, Brookes P, Sergeant R, Santos-Nunez E, Steggar C, Galliford J, et al. De Novo DQ Donor-Specific Antibodies Are Associated With a Significant Risk of Antibody-Mediated Rejection and Transplant Glomerulopathy. Transplantation (2012) 94(2):172-7. doi: 10.1097/TP.0b013e3182543950

5. Lee H, Min JW, Kim JI, Moon IS, Park KH, Yang CW, et al. Clinical Significance of HLA-DQ Antibodies in the Development of Chronic Antibody-Mediated Rejection and Allograft Failure in Kidney Transplant Recipients. Med (Baltimore) (2016) 95(11):e3094. doi: 10.1097/md. 0000000000003094

6. Everly MJ, Rebellato LM, Haisch CE, Ozawa M, Parker K, Briley KP, et al. Incidence and Impact of De Novo Donor-Specific Alloantibody in Primary Renal Allografts. Transplantation (2013) 95(3):410-7. doi: 10.1097/TP. 0b013e31827d62e3

\section{ETHICS STATEMENT}

The studies involving human participants were reviewed and approved by the medical ethics committee of Leiden University Medical Center (Leiden, the Netherlands). The patients/ participants provided their written informed consent to participate in this study.

\section{AUTHOR CONTRIBUTIONS}

$\mathrm{CK}, \mathrm{SH}$, and $\mathrm{FC}$ conceived and designed the study. CK and SB acquired, analyzed, and interpreted the data. The experiments were performed by CK, SB, MF-D, MV, MU-M, and KB. RB provided essential reagents. DR provided HLA typing data. SB, $\mathrm{CK}, \mathrm{SH}$, and $\mathrm{FC}$ wrote the manuscript. DR, RB, and JF critically reviewed the manuscript. All authors contributed to the article and approved the final version of the manuscript.

\section{ACKNOWLEDGMENTS}

The authors thank the Flow cytometry Core Facility of the Leiden University Medical Center and the HLA typing and screening laboratory Leiden, the Netherlands for technical assistance.

\section{SUPPLEMENTARY MATERIAL}

The Supplementary Material for this article can be found online at: https://www.frontiersin.org/articles/10.3389/fimmu.2021. 761893/full\#supplementary-material

7. DeVos JM, Gaber AO, Knight RJ, Land GA, Suki WN, Gaber LW, et al. Donor-Specific HLA-DQ Antibodies may Contribute to Poor Graft Outcome After Renal Transplantation. Kidney Int (2012) 82(5):598-604. doi: 10.1038/ ki.2012.190

8. Ladowski JM, Mullins H, Romine M, Kloda D, Young C, Hauptfeld-Dolejsek V, et al. Eplet Mismatch Scores and De Novo Donor-Specific Antibody Development in Simultaneous Pancreas-Kidney Transplantation. Hum Immunol (2020) 82(3):139-46. doi: 10.1016/j.humimm.2020.12.009

9. Wu Z, Qiu L, Wang C, Liu X, Li Q, Yu S, et al. Clinical and Pathologic Feature of Patients With Early Versus Late Active Antibody-Mediated Rejection After Kidney Transplantation: A Single-Center Experience. Transplant Proc (2021) 53(3):1025-31. doi: 10.1016/j.transproceed.2020.11.004

10. Duquesnoy RJ, Askar M. HLAMatchmaker: A Molecularly Based Algorithm for Histocompatibility Determination. V. Eplet Matching for HLA-DR, HLADQ, and HLA-DP. Hum Immunol (2007) 68(1):12-25. doi: 10.1016/ j.humimm.2006.10.003

11. Duquesnoy RJ. A Structurally Based Approach to Determine HLA Compatibility at the Humoral Immune Level. Hum Immunol (2006) 67 (11):847-62. doi: 10.1016/j.humimm.2006.08.001

12. Kosmoliaptsis V, Mallon DH, Chen Y, Bolton EM, Bradley JA, Taylor CJ. Alloantibody Responses After Renal Transplant Failure Can Be Better Predicted by Donor-Recipient HLA Amino Acid Sequence and Physicochemical Disparities Than Conventional HLA Matching. Am J Transplant (2016) 16(7):2139-47. doi: 10.1111/ajt.13707

13. Lachmann N, Niemann M, Reinke P, Budde K, Schmidt D, Halleck F, et al. Donor-Recipient Matching Based on Predicted Indirectly Recognizable HLA 
Epitopes Independently Predicts the Incidence of De Novo Donor-Specific HLA Antibodies Following Renal Transplantation. Am J Transplant (2017) 17 (12):3076-86. doi: 10.1111/ajt.14393

14. Willicombe M, Blow M, Santos-Nunez E, Freeman C, Brookes P, Taube D. Terasaki Epitope Mismatch Burden Predicts the Development of De Novo DQ Donor-Specific Antibodies and are Associated With Adverse Allograft Outcomes. Transplantation (2018) 102(1):127-34. doi: 10.1097/tp. 0000000000001887

15. Wiebe C, Kosmoliaptsis V, Pochinco D, Gibson IW, Ho J, Birk PE, et al. HLADR/DQ Molecular Mismatch: A Prognostic Biomarker for Primary Alloimmunity. Am J Transplant (2019) 19(6):1708-19. doi: 10.1111/ajt.15177

16. Snanoudj R, Kamar N, Cassuto E, Caillard S, Metzger M, Merville P, et al. Epitope Load Identifies Kidney Transplant Recipients at Risk of Allosensitization Following Minimization of Immunosuppression. Kidney Int (2019) 95(6):1471-85. doi: 10.1016/j.kint.2018.12.029

17. Senev A, Coemans M, Lerut E, Van Sandt V, Kerkhofs J, Daniëls L, et al. Eplet Mismatch Load and De Novo Occurrence of Donor-Specific Anti-HLA Antibodies, Rejection, and Graft Failure After Kidney Transplantation: An Observational Cohort Study. J Am Soc Nephrol (2020) 31(9):2193-204. doi: 10.1681/asn.2020010019

18. Kramer CSM, Roelen DL, Heidt S, Claas FHJ. Defining the Immunogenicity and Antigenicity of HLA Epitopes is Crucial for Optimal Epitope Matching in Clinical Renal Transplantation. HLA (2017) 90(1):5-16. doi: 10.1111/ $\tan .13038$

19. Lemieux W, Mohammadhassanzadeh H, Klement W, Daniel C, SapirPichhadze R. Matchmaker, Matchmaker Make Me a Match: Opportunities and Challenges in Optimizing Compatibility of HLA Eplets in Transplantation. Int J Immunogenet (2021) 48(2):135-44. doi: 10.1111/iji.12525

20. Duquesnoy RJ, Marrari M, Tambur AR, Mulder A, Sousa LC, da Silva AS, et al. First Report on the Antibody Verification of HLA-DR, HLA-DQ and HLA-DP Epitopes Recorded in the HLA Epitope Registry. Hum Immunol (2014) 75(11):1097-103. doi: 10.1016/j.humimm.2014.09.012

21. Duquesnoy RJ, Marrari M, Mulder A, Sousa LC, da Silva AS, do Monte SJ. First Report on the Antibody Verification of HLA-ABC Epitopes Recorded in the Website-Based HLA Epitope Registry. Tissue Antigens (2014) 83(6):391400. doi: $10.1111 / \tan .12341$

22. Duquesnoy RJ, Marrari M, Marroquim MS, Borges AG, da Mata Sousa LCD, Socorro A, et al. Second Update of the International Registry of HLA Epitopes. I. The HLA-ABC Epitope Database. Hum Immunol (2019) 80(2):103-6. doi: 10.1016/j.humimm.2018.11.007

23. Duquesnoy RJ, Marrari M, Mulder A, Claas FH, Mostecki J, Balazs I. Structural Aspects of Human Leukocyte Antigen Class I Epitopes Detected by Human Monoclonal Antibodies. Hum Immunol (2012) 73(3):267-77. doi: 10.1016/j.humimm.2011.11.011

24. Duquesnoy RJ, Mulder A, Askar M, Fernandez-Vina M, Claas FH. HLAMatchmaker-Based Analysis of Human Monoclonal Antibody Reactivity Demonstrates the Importance of an Additional Contact Site for Specific Recognition of Triplet-Defined Epitopes. Hum Immunol (2005) 66 (7):749-61. doi: 10.1016/j.humimm.2005.04.002

25. Duquesnoy RJ, Honger G, Hosli I, Marrari M, Schaub S. Detection of Newly Antibody-Defined Epitopes on HLA Class I Alleles Reacting With Antibodies Induced During Pregnancy. Int J Immunogenet (2016) 43(4):200-8. doi: $10.1111 / \mathrm{iji} .12280$

26. El-Awar N, Lee JH, Tarsitani C, Terasaki PI. HLA Class I Epitopes: Recognition of Binding Sites by Mabs or Eluted Alloantibody Confirmed With Single Recombinant Antigens. Hum Immunol (2007) 68(3):170-80. doi: 10.1016/j.humimm.2006.11.006

27. El-Awar NR, Akaza T, Terasaki PI, Nguyen A. Human Leukocyte Antigen Class I Epitopes: Update to 103 Total Epitopes, Including the C Locus. Transplantation (2007) 84(4):532-40. doi: 10.1097/01.tp.0000278721. 97037.1e

28. Sapir-Pichhadze R, Zhang X, Ferradji A, Madbouly A, Tinckam KJ, Gebel HM, et al. Epitopes as Characterized by Antibody-Verified Eplet Mismatches Determine Risk of Kidney Transplant Loss. Kidney Int (2020) 97(4):778-85. doi: 10.1016/j.kint.2019.10.028

29. Wiebe C, Rush DN, Nevins TE, Birk PE, Blydt-Hansen T, Gibson IW, et al. Class II Eplet Mismatch Modulates Tacrolimus Trough Levels Required to
Prevent Donor-Specific Antibody Development. J Am Soc Nephrol (2017) 28 (11):3353-62. doi: 10.1681/asn.2017030287

30. Davis S, Wiebe C, Campbell K, Anobile C, Aubrey M, Stites E, et al. Adequate Tacrolimus Exposure Modulates the Impact of HLA Class II Molecular Mismatch: A Validation Study in an American Cohort. Am J Transplant (2021) 21(1):322-8. doi: 10.1111/ajt.16290

31. Duquesnoy RJ, Marrari M, Jelenik L, Zeevi A, Claas FH, Mulder A. Structural Aspects of HLA Class I Epitopes Reacting With Human Monoclonal Antibodies in Ig-Binding, C1q-Binding and Lymphocytotoxicity Assays. Hum Immunol (2013) 74(10):1271-9. doi: 10.1016/j.humimm.2013.05.016

32. El-Awar N, Nguyen A, Almeshari K, Alawami M, Alzayer F, Alharbi M, et al. HLA Class II DQA and DQB Epitopes: Recognition of the Likely Binding Sites of HLA-DQ Alloantibodies Eluted From Recombinant HLA-DQ Single Antigen Cell Lines. Hum Immunol (2013) 74(9):1141-52. doi: 10.1016/ j.humimm.2013.05.013

33. Duquesnoy RJ, Hönger G, Hösli I, Marrari M, Schaub S. Antibody-Defined Epitopes on HLA-DQ Alleles Reacting With Antibodies Induced During Pregnancy and the Design of a DQ Eplet Map. Hum Immunol (2016) 77 (10):824-31. doi: 10.1016/j.humimm.2016.06.021

34. Duquesnoy RJ, Honger G, Hosli I, Marrari M, Schaub S. Identification of Epitopes on HLA-DRB Alleles Reacting With Antibodies in Sera From Women Sensitized During Pregnancy. Hum Immunol (2016) 77(2):214-22. doi: 10.1016/j.humimm.2015.12.002

35. Kramer CSM, Franke-van Dijk MEI, Bakker KH, Uyar-Mercankaya M, Karahan GE, Roelen DL, et al. Generation and Reactivity Analysis of Human Recombinant Monoclonal Antibodies Directed Against Epitopes on HLA-Dr. Am J Transplant (2020) 20(12):3341-53 . doi: 10.1111/ajt.15950

36. Wen L, Hanvanich M, Werner-Favre C, Brouwers N, Perrin LH, Zubler RH. Limiting Dilution Assay for Human B Cells Based on Their Activation by Mutant EL4 Thymoma Cells: Total and Anti-Malaria Responder B Cell Frequencies. Eur J Immunol (1987) 17(6):887-92. doi: 10.1002/eji.1830170624

37. Lighaam LC, Vermeulen E, Bleker T, Meijlink KJ, Aalberse RC, Barnes E, et al. Phenotypic Differences Between IgG4+ and IgG1+ B Cells Point to Distinct Regulation of the IgG4 Response. J Allergy Clin Immunol (2014) 133(1):26770 e1-6. doi: 10.1016/j.jaci.2013.07.044

38. Heidt S, Roelen DL, Eijsink C, Eikmans M, van Kooten C, Claas FH, et al. Calcineurin Inhibitors Affect B Cell Antibody Responses Indirectly by Interfering With T Cell Help. Clin Exp Immunol (2010) 159(2):199-207. doi: 10.1111/j.1365-2249.2009.04051.x

39. Kramer CSM, Franke-van Dijk MEI, Priddey AJ, Pongracz T, Gnudi E, Car H, et al. Recombinant Human Monoclonal HLA Antibodies of Different IgG Subclasses Recognising the Same Epitope: Excellent Tools to Study Differential Effects of Donor-Specific Antibodies. HLA (2019) 94(5):415-24. doi: $10.1111 / \tan .13664$

40. Vink T, Oudshoorn-Dickmann M, Roza M, Reitsma JJ. De Jong RN. A Simple, Robust and Highly Efficient Transient Expression System for Producing Antibodies. Methods (2014) 65(1):5-10. doi: 10.1016/j.ymeth.2013.07.018

41. Ye J, Ma N, Madden TL, Ostell JM. IgBLAST: An Immunoglobulin Variable Domain Sequence Analysis Tool. Nucleic Acids Res (2013) 41(Web Server issue):W34-40. doi: 10.1093/nar/gkt382

42. Kramer CSM, Koster J, Haasnoot GW, Roelen DL, Claas FHJ, Heidt S. HLAEMMA: A User-Friendly Tool to Analyse HLA Class I and Class II Compatibility on the Amino Acid Level. HLA (2020) 96(1):43-51. doi: $10.1111 / \tan .13883$

43. Guex N, Peitsch MC. SWISS-MODEL and the Swiss-PdbViewer: An Environment for Comparative Protein Modeling. Electrophoresis (1997) 18 (15):2714-23. doi: 10.1002/elps.1150181505

44. Tambur AR, Rosati J, Roitberg S, Glotz D, Friedewald JJ, Leventhal JR. Epitope Analysis of HLA-DQ Antigens: What Does the Antibody See? Transplantation (2014) 98(2):157-66. doi: 10.1097/tp.0000000000000220

45. Youngs D, Warner P, Gallagher M, Gimferrer I. New DQA1 Allele Specific Antibody Against Epitope 2D (an Exon 1 Encoded Amino Acid). Considerations for Alleles Under the Same P-Group Designation. Transpl Immunol (2018) 51:32-9. doi: 10.1016/j.trim.2018.08.007

46. McCaughan JA, Battle RK, Singh SKS, Tikkanen JM, Moayedi Y, Ross HJ, et al. Identification of Risk Epitope Mismatches Associated With De Novo Donor-Specific HLA Antibody Development in Cardiothoracic 
Transplantation. Am J Transplant (2018) 18(12):2924-33. doi: 10.1111/ ajt.14951

47. Tambur AR, Leventhal JR, Friedewald JJ, Ramon DS. The Complexity of Human Leukocyte Antigen (HLA)-DQ Antibodies and its Effect on Virtual Crossmatching. Transplantation (2010) 90(10):1117-24. doi: 10.1097/ TP.0b013e3181f89c6d

48. Amit AG, Mariuzza RA, Phillips SE, Poljak RJ. Three-Dimensional Structure of an Antigen-Antibody Complex at 2.8 A Resolution. Science (1986) 233 (4765):747-53. doi: 10.1126/science.2426778

49. Ippolito GC, Schelonka RL, Zemlin M, Ivanov II, Kobayashi R, Zemlin C, et al. Forced Usage of Positively Charged Amino Acids in Immunoglobulin CDRH3 Impairs B Cell Development and Antibody Production. J Exp Med (2006) 203(6):1567-78. doi: 10.1084/jem.20052217

50. Xu JL, Davis MM. Diversity in the CDR3 Region of V(H) is Sufficient for Most Antibody Specificities. Immunity (2000) 13(1):37-45. doi: 10.1016/s10747613(00)00006-6

51. Tassone G, De Santis D, Vukovic I, Downing J, Martinez OP, D’Orsogna LJ. Different Eplet Software Programs Give Discordant and Incorrect Results: An Analysis of HLAMatchmaker vs Fusion Matchmaker Eplet Calling Software. HLA (2020) 96(1):52-63. doi: 10.1111/tan.13897

52. Gu Y, Wong YH, Liew CW, Chan CEZ, Murali TM, Yap J, et al. Defining the Structural Basis for Human Alloantibody Binding to Human Leukocyte Antigen Allele HLA-A*11:01. Nat Commun (2019) 10(1):893. doi: 10.1038/ s41467-019-08790-1

53. Benjamin DC, Perdue SS. Site-Directed Mutagenesis in Epitope Mapping. Methods (1996) 9(3):508-15. doi: 10.1006/meth.1996.0058

54. Lutz CT, Smith KD, Greazel NS, Mace BE, Jensen DA, McCutcheon JA, et al. Bw4-Reactive and Bw6-Reactive Antibodies Recognize Multiple Distinct HLA Structures That Partially Overlap in the Alpha-1 Helix. J Immunol (1994) 153 (9):4099-110.

55. Mallon DH, Bradley JA, Winn PJ, Taylor CJ, Kosmoliaptsis V. ThreeDimensional Structural Modelling and Calculation of Electrostatic Potentials of HLA Bw4 and Bw6 Epitopes to Explain the Molecular Basis for Alloantibody Binding: Toward Predicting HLA Antigenicity and Immunogenicity. Transplantation (2015) 99(2):385-90. doi: 10.1097/ tp.0000000000000546
56. Sanchez-Mazas A, Nunes JM, Middleton D, Sauter J, Buhler S, McCabe A, et al. Common and Well-Documented HLA Alleles Over All of Europe and Within European Sub-Regions: A Catalogue From the European Federation for Immunogenetics. HLA (2017) 89(2):104-13. doi: 10.1111/tan.12956

57. Hurley CK, Kempenich J, Wadsworth K, Sauter J, Hofmann JA, Schefzyk D, et al. Common, Intermediate and Well-Documented HLA Alleles in World Populations: CIWD Version 3.0.0. HLA (2020) 95(6):516-31. doi: 10.1111/tan.13811

58. Kramer CSM, Israeli M, Mulder A, Doxiadis IIN, Haasnoot GW, Heidt S, et al. The Long and Winding Road Towards Epitope Matching in Clinical Transplantation. Transpl Int (2019) 32(1):16-24. doi: 10.1111/tri.13362

59. Schawalder L, Hönger G, Kleiser M, van Heck MR, van de Pasch LAL, Vendelbosch S, et al. Development of an Immunogenicity Score for HLA-DQ Eplets: A Conceptual Study. HLA (2021) 97(1):30-43. doi: 10.1111/tan.14110

60. Geneugelijk K, Spierings E. PIRCHE-II: An Algorithm to Predict Indirectly Recognizable HLA Epitopes in Solid Organ Transplantation. Immunogenetics (2020) 72(1-2):119-29. doi: 10.1007/s00251-019-01140-x

\section{Conflict of Interest: RB is employed by Pure Protein LLC.}

The remaining authors declare that the research was conducted in the absence of any commercial or financial relationships that could be construed as a potential conflict of interest.

Publisher's Note: All claims expressed in this article are solely those of the authors and do not necessarily represent those of their affiliated organizations, or those of the publisher, the editors and the reviewers. Any product that may be evaluated in this article, or claim that may be made by its manufacturer, is not guaranteed or endorsed by the publisher.

Copyright $\odot 2022$ Bezstarosti, Kramer, Franke-van Dijk, Vergunst, Bakker, UyarMercankaya, Buchli, Roelen, de Fijter, Claas and Heidt. This is an open-access article distributed under the terms of the Creative Commons Attribution License (CC BY). The use, distribution or reproduction in other forums is permitted, provided the original author(s) and the copyright owner(s) are credited and that the original publication in this journal is cited, in accordance with accepted academic practice. No use, distribution or reproduction is permitted which does not comply with these terms. 